UCRL-CR-121294

PREPRINT

\title{
Optimization of X-ray Sources for Proximity Lithography Produced by a High Average Power Nd:Glass Laser
}

\author{
P. Celliers, L.B. Da Silva, C.B. Dane, S. Mrowka, M. Norton, J. Harder, \\ L. Hackel and D. Matthews \\ University of California, Lawrence Livermore National Laboratory, \\ Livermore, CA 94550
}

H. Fiedorowicz and A. Bartnick

Military University of Technology, Institute of Optoelectronics,

Laser Plasma Interaction Section, 01-489 Warsaw 49, Poland

\section{J. Maldonado}

I.B.M. Microelectronics, Rte 52, Hopewell Junction, NY, 12533

\section{J. Abate}

600 Mountain Ave., AT\&T Bell Labos, Murray Hill, New Jersey, 07974

This paper was prepared for submittal to:

U.S. Department of Defense

Advanced Research Projects Agency

$$
\underset{\text { July } 1995}{\text { Arling }} \text { VA }
$$

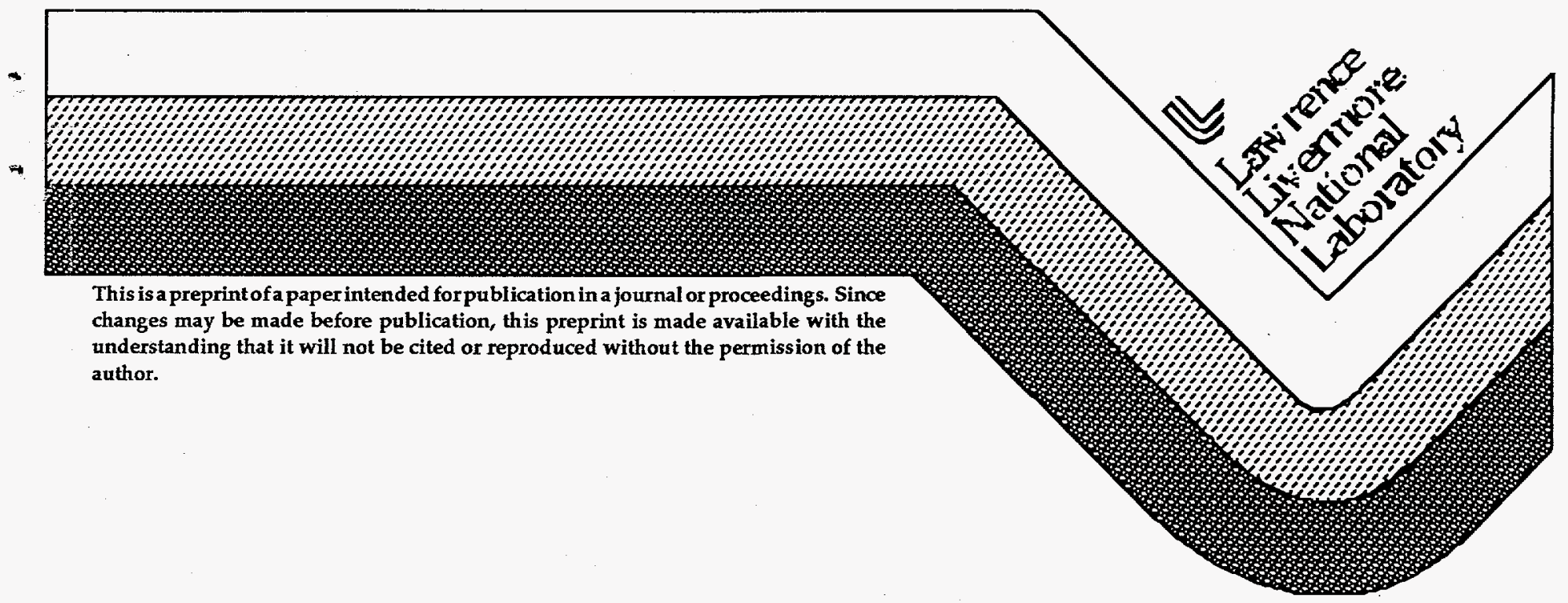




\section{DISCLAIMER}

This report was prepared as an account of work sponsored by an agency of the United States Government. Neither the United States Government nor any agency thereof, nor any of their employees, make any warranty, express or implied, or assumes any legal liability or responsibility for the accuracy, completeness, or usefulness of any information, apparatus, product, or process disclosed, or represents that its use would not infringe privately owned rights. Reference herein to any specific commercial product, process, or service by trade name, trademark, manufacturer, or otherwise does not necessarily constitute or imply its endorsement, recommendation, or favoring by the United States Government or any agency thereof. The views and opinions of authors expressed herein do not necessarily state or reflect those of the United States Government or any agency thereof. 


\section{DISCLAIMER}

Portions of this document may be illegible in electronic image products. Images are produced from the best available original document. 


\title{
Optimization of $x$-ray sources for proximity lithography produced by a high average power Nd:glass laser*
}

\author{
P. Celliers, L. B. DaSilva, C. B. Dane, S. Mrowka, M. Norton, J. Harder, L. \\ Hackel and D. Matthews \\ University of California, Lawrence Livermore National Laboratory, \\ Livermore, $C A 94550$ \\ H. Fiedorowicz and A. Bartnick \\ Military University of Technology, Institute of Optoelectronics, \\ Laser Plasma Interaction Section, 01-489 Warsaw 49, Poland \\ J. Maldonado \\ IBM Microelectronics, Rte 52, Hopewell Junction, NY, 12533
}

J. Abate

600 Mountain Ave., ATET Bell Labs. Murray Hill, New Jersey, 07974

\begin{abstract}
We measured the conversion efficiency of laser pulse energy into $x$ rays from a variety of solid planar targets and a Xe gas puff target irradiated using a high average power Nd:glass slab laser capable of delivering $13 \mathrm{~ns}$ FWHM pulses at up to $20 \mathrm{~J}$ at $1.053 \mu \mathrm{m}$ and $12 \mathrm{~J}$ at 0.53 $\mu \mathrm{m}$. Targets where chosen to optimize emission in the 9-19 $\AA$ wavelength band, including $L$-shell emission from materials with atomic numbers in the $Z=24-30$ and $M$-shell emission from $X e(Z=54)$. With $1.053 \mu \mathrm{m}$ a maximum conversion of $10 \%$ into $2 \pi$ sr was measured from solid Xe and type 302 stainless steel targets. At 0.527 $\mu \mathrm{m}$ efficiencies of $12-18 \% /(2 \pi \mathrm{sr})$ were measured for all of the solid targets in the same wavelength band. The $x$-ray conversion efficiency from the Xe gas puff target was considerably lower, at about $3 \% /(2 \pi \mathrm{sr})$ when irradiated with $1.053 \mu \mathrm{m}$.
\end{abstract}

\footnotetext{
* This research was performed for the U.S. Department of Defense Advanced Research Projects Agency under ARPA Order No. A251
} 
X-ray sources for proximity lithography

\section{INTRODUCTION}

The concept of a laser-based proximity lithography system has advanced to the point that a detailed design of a prototype system capable of exposing 40 wafer levels per hour at $0.12 \mu \mathrm{m}$ feature size appears to be technically feasible with high average power laser technology. Various technological choices need to be made regarding the specific laser driver technology to be used and specific target material and design. The research described in this report focused on measuring and optimizing the $x$-ray yields produced with one particular choice of laser driver intended for $x$-ray production in a proximity lithography system.

$X$-ray yields from laser-produced plasmas have been investigated in great detail for nearly two decades, and have been examined over a wide variety of laser parameters (wavelength, pulse duration, focused intensity) as well as target material and $x$-ray emission wavelengths. ${ }^{1-10}$ A number of studies have focused specifically on lithography applications to match target materials with realistic laser parameters in order to produce the required $x$-ray spectrum (keV $x$-rays) at an acceptable yield. ${ }^{11-17} \mathrm{X}$-rays from laser-produced plasmas in the $1 \mathrm{keV}$ energy range required for proximity lithography are produced most efficiently with focused laser intensities around $10^{13} \mathrm{~W} / \mathrm{cm}^{2}$ and from targets with atomic number in the range $Z=26-30$ (Ne-like ions, $L$ shell emission) or $Z=53-56$ ( $\mathrm{Ni}$-like ions, $\mathrm{M}$-shell emission). As a general finding, $x$-ray yields are known to improve substantially with decreasing laser wavelength. $2,3,5$-ray yields from laser-produced plasmas also depend on the pulse duration which determines the characteristic plasma volume achieved during the pulse. High conversion efficiency (better than $10 \% / 2 \pi \mathrm{sr}$ ) has been usually observed with moderate duration pulses $(0.5-10 \mathrm{~ns}) .9,14$ However, high conversion efficiency can also be achieved with shorter pulses $(<100 \mathrm{ps})$ in combination with a weak prepulse to generate a long scalelength plasma. 10,18 For pulses longer than $10 \mathrm{~ns}$ it is not clear, from the findings of previous studies, whether high conversion efficiency can be achieved. Early experiments with $8 \mathrm{~ns} \mathrm{Nd}$ :glass laser pulses indicated that efficiencies around $8 \% / 2 \pi$ sr could be achieved; ${ }^{1}$ however, experiments with $30 \mathrm{~ns} \mathrm{KrF}$ pulses focused to more than $10^{14} \mathrm{~W} / \mathrm{cm}^{2}$ failed to achieve yields comparable to measurements with shorter pulses at the same wavelength. ${ }^{15}$ A practical 
X-ray sources for proximity lithography limit on the pulse duration of less than about $5 \mathrm{~ns}$ was suggested by Chaker $e t$ al. ${ }^{17}$, although this conclusion was tentative in the absence of experimental data. The requirements of high average power with high focused intensities and moderate pulse duration are potentially in conflict with the pulse parameters of current high average power laser technology, which operate more reliably with rather long pulse durations in the range of $10-15 \mathrm{~ns}$ duration for $\mathrm{Nd}$ :glass technology and 25 - $30 \mathrm{~ns}$ for excimer lasers.

One potential laser driver for proximity lithography is a high average power Nd:glass slab design operating with high pulse energy and moderate repetition rate. Currently the most advanced realization of this technology is . available at Lawrence Livermore National Laboratory, ${ }^{19}$ and consists of a flashlamp pumped system capable of producing near diffraction-limited pulses with approximately $13 \mathrm{~ns}$ FWHM duration at energies of around $20 \mathrm{~J}$ at a rate of $6 \mathrm{~Hz}$ to produce an average power of $120 \mathrm{~W}$. The design is scalable to higher average power by increasing the pulse energy and/or repetition rate; average powers approaching $2 \mathrm{~kW}$ are envisioned. An important characteristic of this high average power capability is the utilization of phase conjugate wavefront correction ${ }^{20}$ to ensure a uniform intensity and a near ideal phase front in the final pass of the slab amplifier, which is necessary to ensure reliable operation. This technology operates most effectively with a rather long pulse duration of 12 - $14 \mathrm{~ns}$, which raises the issue of whether the $\mathrm{x}$-ray yields produced with this laser can approach the maximum yields observed with shorter pulses. This question was examined experimentally in the work described in this report.

In this study we measured and optimized the $x$-ray conversion from several L-shell emitters ( $\mathrm{Fe}, \mathrm{Cu}, \mathrm{Zn}$, brass, stainless steel), and one $\mathrm{M}$-shell emitter $(\mathrm{Xe})$. The studies with $\mathrm{Xe}$ included measurements from a cryogenic solid target as well as a preliminary investigation of a gas puff target. Both forms of the Xe target offer the potential to design a source with considerably reduced debris generation. All targets were investigated at two operating wavelengths of the laser: the fundamental wavelength $1.053 \mu \mathrm{m}$; and the second harmonic, $0.527 \mu \mathrm{m}$. 
X-ray sources for proximity lithography

\section{EXPERIMENT}

The experiments utilized several diagnostics and target configurations, which we describe in detail in this section. We measured absolute $x$-ray yields using a set of absolutely calibrated and filtered photoconductive diamond (PCD) detectors. We also measured the $x$-ray spectrum for each target type and for all variations of other input parameters, such as laser pulse energy, wavelength and focusing conditions; the detailed emission spectra were found to vary with all of these parameters. We used the measured spectra in the analysis of the data produced by the PCD detectors. This was essential to obtain accurate measruements since the x-ray fluence striking each PCD detector depended on both the filter transmission function and the detailed emission spectrum of the source.

\section{II (a) Laser parameters}

For the experiments with solid planar targets the experimental layout is shown in Figure 1. The laser was focused through a $330 \mathrm{~mm}$ lens into the center of the experimental chamber onto a planar target oriented at $45^{\circ}$ to the laser axis. Laser energy was monitored with a fast pyroelectric detector, and cross-calibrated with a calorimetric energy meter. Pulse energy was variable from about $1-20 \mathrm{~J}$ at $1.053 \mu \mathrm{m}$, and $0.5-12 \mathrm{~J}$ at $0.527 \mu \mathrm{m}$ wavelength. The beam delivered to the target chamber was square in cross-section measuring $25 \mathrm{~mm}$ on each side, and produced an $\mathrm{f} / 13$ focus with the $330 \mathrm{~mm}$ focal length lens we used. The beam focus was adjusted by translating the lens. In a separate test of the beam quality the far field pattern of the $0.527 \mu \mathrm{m}$ beam focused with the $330 \mathrm{~mm}$ lens was imaged onto a CCD camera using a wellcorrected microscope objective. At best focus we found that $80 \%$ of the beam energy was contained within a diameter of $27 \mu \mathrm{m}$, equivalent to about $1.5 \mathrm{x}$ the diffraction limit. The maximum focused intensities achieved with this beam quality reach as high as $7 \times 10^{13} \mathrm{~W} / \mathrm{cm}^{2}$ for $1.053 \mu \mathrm{m}$ and $2 \times 10^{14} \mathrm{~W} / \mathrm{cm}^{2}$ for $0.527 \mu \mathrm{m}$ light. These peak intensities meet or exceed the intensities required to obtain high $\mathrm{x}$-ray yields in the $\mathrm{keV}$ range.

\section{II (b) Solid targets}

The target mount consisted of an $x-y-z$ translation stage with an aluminum mounting frame for attaching the target. Motion in a plane 
X-ray sources for proximity lithography parallel to the target surface $(x-y)$ allowed us to position a fresh surface of the target in the beam for each shot while maintaining the same axial position relative to the laser focus.' All of the solid targets were available in the form of tapes or thin plates which could be mounted directly on the frame. For most of these materials the target thickness was much larger than typical ablation depths. However in the particular case of Fe the target consisted of a thin layer of 3-5 $\mu \mathrm{m}$ of Fe powder bonded to a mylar tape substrate. This "mass limited" target is designed to provide enough material to produce $x$ rays while limiting debris production.

In the particular case of solid Xe the target apparatus consisted of a $1 \mathrm{~mm}$. thick copper plate connected to a cold finger with a length of copper braid, and cooled to approximately $20 \mathrm{~K}$. A solid Xe layer was formed by condensing $\mathrm{Xe}$ gas onto the cryogenic surface to produce a thin (approximately $100 \mu \mathrm{m}$ thick) layer on the copper substrate. Although the melting point of Xe (at atmospheric pressure) is around $160 \mathrm{~K}$, a temperature of $20 \mathrm{~K}$ was required in vacuum in order to maintain a low enough $X e$ vapor pressure to produce a stable condensed layer on the copper substrate and to minimize reabsorption of the Xe x-ray emission by residual cold Xe gas in the chamber.

\section{II (c) Gas puff target}

The gas puff valve used to examine yields from $X \mathrm{e}$ gas has been described in previous work. ${ }^{21}$ It was supplied with a reservoir of Xe maintained at 10 atm, and produced gas pulses lasting for several hundred $\mu$ s duration from nozzle apertures varying from $500 \mu \mathrm{m}$ to $1000 \mu \mathrm{m}$ in diameter. The nozzle from the gas puff valve was oriented coaxially relative to the laser beam with the beam directed straight into the nozzle (Figure 2). X-ray yield was monitored with a PCD array placed to view the plasma from an orientation perpendicular to the laser axis and situated at the nozzle exit. The $x$-ray spectrometer and the pinhole camera also viewed plasma from a perpendicular orientation to the axis and at different azimuthal positions.

\section{II (d) Curved crystal spectrograph}

A curved potassium acid pthalate (KAP) crystal spectrograph recorded $x-$ ray spectra from a direction of $90^{\circ}$ relative to the laser axis and $45^{\circ}$ to the target 
X-ray sources for proximity lithography normal. The spectrometer consisted of three separate KAP crystals each bent to a radius of $79 \mathrm{~mm}$, situated about $350 \mathrm{~mm}$ from the plasma. A high resolution CCD camera system operating with 16-bit readout resolution ${ }^{22}$ was used to record the spectra. The detector consisted of a backilluminated Tektronix TK1024 CCD chip. The system was sensitive enough so that all spectra recorded in these experiments were produced with a single laser pulse. To obtain the complete spectrum the KAP crystals were placed at slightly different standoff distances from the plasma to sample the 9 - $19 \AA$ spectral region in overlapping segments. To block out visible and UV portions of the spectrum one or two layers of a light tight aluminized mylar film $(5000 \AA$ $\mathrm{Al} / 1.5 \mu \mathrm{m}$ mylar) was placed at the entrance to the spectrograph. This film . wạs subject to occasional damage from target debris, and was checked and replaced at appropriate intervals.

We performed wavelength calibration of the spectrometer by identifying known features of the $\mathrm{Fe}$ and $\mathrm{Cu} \mathrm{L}$-shell spectrum and applying a low order polynomial mapping from detector position to a wavelength scale. Within the 9-19 $\AA$ band the CCD array detector responds linearly to the $x$-ray fluence independent of wavelength. We corrected the raw data to account for the filter transmission and the KAP crystal reflectivity. The aluminized mylar transmission was independently calibrated at an in-house facility to determine its transmission over the 9-19 $\AA$ wavelength band. The KAP reflectivity has been previously calibrated by Henke et al. 23

\section{II (e) Absolutely calibrated PCD and yield measurements}

$X$-ray yields were recorded with a set of 4 filtered type IIA photoconductive diamond (PCD) detectors. ${ }^{24}$ These were mounted in a compact $2 \times 2$ square array situated $15.9 \mathrm{~cm}$ from the target at an angle approximately normal to the target surface. For all measurements the PCDs were biased with $600 \mathrm{~V}$, and the signal was coupled through a capacitor into a $50 \mathrm{ohm}$ cable connected to a high speed digital oscilloscope for recording. These detectors have been used in a number of previous $x$-ray yield experiments at LLNL, ${ }^{25}$ and have been absolutely calibrated. 26 Within the 9-19 $\AA$ wavelength band observed in these measurements they have a flat wavelength response. For the bias conditions and spectral range used in the measurements reported in this work the sensitivity of these devices was nominally $7.5 \times 10^{-4} \mathrm{~A} / \mathrm{W}$. An 
$X$-ray sources for proximity lithography uncertainty of approximately $20 \%$ on this value as reported in the original absolute calibration was assumed.

Examples of a PCD signal trace and a trace of the laser pulse recorded on high speed oscilloscopes are shown in Figure 3. The $x$-ray pulses displayed the same temporal structure, if any, that was produced in the laser pulses. The FWHM pulse duration of the $x$-ray signals observed from solid targets was similar to but somewhat shorter than the laser pulse by an amount of approximately $20 \%-30 \%$. Hence the x-ray pulses from solids were typically 10 ns FWHM, while the laser pulse was 12 - 14 ns FWHM.

We monitored contributions from various parts of the $x$-ray spectrum using a set of four different filters on the PCD detector array. The filter materials and thicknesses used are displayed in table I. The filter foils were mounted on $9 \mathrm{~mm}$ diameter washers with $5 \mathrm{~mm}$ diameter apertures to allow easy manipulation and placement in the detector housing. All of these foils were manufactured commercially by vacuum evaporation; 27 furthermore, all foils of each type originated from the same batch in the fabrication process. Several samples from each filter type were separately calibrated at a facility at LLNL to determine an accurate thickness. Prior to all measurements we performed a cross-calibration of the individual PCD sensitivities. To do this we placed nominally identical $2 \mu \mathrm{m} \mathrm{Zn}$ filters on all detectors and recorded signals from a Fe or type 302 stainless steel laser-produced plasma. Several data points were taken for each of 3 rearrangements of the individual filters in the filter set so that we could eliminate effects due to variability in the filter transmission. We found a variation in detector sensitivity among the four devices used in this work amounting to a $\pm 20 \%$ spread. The extracted filter transmissions were also consistent with a $10-15 \%$ variability from one piece to the next. Based on these uncertainties alone, the absolute uncertainty in yield for these measurements is around $\pm 25 \%$. However, relative uncertainties (comparison of different target materials or laser parameters) were around $10 \%$, which was determined primarily by shot-to-shot variations.

To determine the absolute $x$-ray yield, we integrated the recorded oscilloscope signals to produce a value proportional to the total $\mathrm{x}$-ray fluence striking the detector. We then converted this raw data to an absolute 
X-ray sources for proximity lithography measure of the $\mathrm{x}$-ray fluence by factoring in corrections to account for detector sensitivity, solid angle, filter transmission and the emission spectrum. Simultaneous measurement of the spectrum is crucial for an accurate determination of the fractional weight of the spectrum viewed by each channel. We determined $x$-ray yields by weighting each detector signal by a factor inversely proportional to the known filter response multiplied by the measured spectrum at each incident energy. We then obtained the resulting conversion efficiency from an average of the contributions measured from each channel, and the known input laser energy.

The CCD detector on the spectrometer also provided an accurate method of assessing relative $x$-ray yields (from one target to the next, or for changes in ' other parameters, such as laser energy). This provided us with a cross-check against the yields inferred on the basis of the PCD measurements. We found good agreement between the relative yields determined from integrating the spectrum recorded on the CCD, and the signals measured with the PCD array.

\section{II (f) Pinhole camera}

We monitored plasma source size with an $x$-ray pinhole camera coupled to a video CCD and a computer-controlled readout. The pinhole was placed about $3 \mathrm{~cm}$ from the target and operated at a magnification of 2-3. The x-ray spectrum was filtered with $18 \mu \mathrm{m} \mathrm{Al}$ foil hence was sensitive mostly to the 8 $12 \AA$ portion of the emitted spectrum.

\section{METHODS}

\section{III (a) Planar solid target optimization}

For each target type and laser wavelength investigated (except the gas puff source) the $x$-ray yield was optimized and measured with a standard procedure consisting of two parts. Firstly, we conducted a focal scan consisting of a series of shots examining yield as a function of axial lens position at maximum laser energy ( $20 \mathrm{~J}$ at $1.053 \mu \mathrm{m}$ and $12 \mathrm{~J}$ at $0.527 \mu \mathrm{m})$. The lens position corresponding to maximum yield as determined from the PCD measurements was identified from this procedure. Secondly, we fixed the lens at its optimum position and measured $x$-ray yield while the laser energy was varied throughout the available range below the maximum setting. 
X-ray sources for proximity lithography Laser energy was easily adjusted by rotating a waveplate within the preamplifier chain to control the pulse energy prior to the final amplifier passes. Both the temporal pulse shape and spatial beam parameters (focus position) were unaffected by this adjustment.

An example of the variation of $x$-ray yield with lens position is displayed in Figure 4, for $\mathrm{Cu}$ and type 302 stainless steel irradiated with $1.053 \mu \mathrm{m}$ laser light. We found in general that the $x$-ray yield reached a broad maximum within a $\pm 1 \mathrm{~mm}$ range of the lens focus. The position of optimum conversion was largely independent of the target material, varying by an amount of approximately $\pm 0.5 \mathrm{~mm}$ for different materials.

"Pinhole photographs of the $x$-ray source region throughout the focal scans for both $1.053 \mu \mathrm{m}$ and $0.527 \mu \mathrm{m}$ are shown in Figures 5 and 6 respectively. The double lobed structure apparent at lens positions of 14 and $15 \mathrm{~mm}$ in Figure 5 originates from the intensity distribution in the square beam as it approaches the focus. Similar lobed structures evident in the $0.527 \mu \mathrm{m}$ scan also originate from laser intensity modulations near best focus, although the pattern is less regular. Also plotted in Figures 5 (b) and $6(\mathrm{~b})$ is the variation of $x$-ray source size measured in these focal scans. The emitting region of the plasma is considerably larger than the beam diameter close to best focus since under no conditions did we observe an $x$-ray source region smaller than about $150 \mu \mathrm{m}$ in diameter, a value which is 3-5 times larger than the beam diameter expected at best focus for the $1.5 \times$ diffraction limited beam. To analyze these images we assumed that the size of the $x$-ray emitting region correlated with the spatial extent of the laser intensity distribution illuminating the plasma. We took the the point where the observed source diameter reached a minimum to be the lens position corresponding to best focus. Using this to identify the focus we also display the geometrical extent of the focal cone for the $f / 13$ focus in these figures for comparison with the data. It is evident that the emitting plasma region is larger than the beam diameter throughout most of the range of lens positions where significant $x$ ray emission was observed.

The most important information from these sequences is an assessment of the size of the $x$-ray emitting region in the source, and an approximate idea of the laser intensity illuminating the plasma at these optimum positions. At 
$X$-ray sources for proximity lithography

the lens position corresponding to the optimum $x$-ray yield the diameter of the source region evident in these sequences is around $280 \mu \mathrm{m}$ for $1.053 \mu \mathrm{m}$ laser light and $240 \mu \mathrm{m}$ for $0.527 \mu \mathrm{m}$ light. It is also evident that the lens position corresponding to best yield does not correspond to the position of best focus, although it is much closer to best focus for $0.527 \mu \mathrm{m}$ light than for $1.053 \mu \mathrm{m}$ light. ( $X$-ray yield on the converging side of the $1.053 \mu \mathrm{m}$ focused beam should be similar to the diverging side; for all measurements reported here the beam was focused on target with a diverging focus.) Average beam intensities illuminationg the plasma at these lens positions can be estimated from the geometrical extent of the focal cone and the distance of the optimum lens position from best focus. For $1.053 \mu \mathrm{m}$ the beam size at optimum focus . wạs $\sim 190 \mu \mathrm{m}$ diameter, to produce a beam intensity $\sim 5 \times 10^{12} \mathrm{~W} / \mathrm{cm}^{2}$. For $0.527 \mu \mathrm{m}$ light the beam diameter was approximately $100 \mu \mathrm{m}$, a factor of two smaller than for the optimum $1.053 \mu \mathrm{m}$ situation, producing intensities $\sim 1.2 \mathrm{x}$ $10^{13} \mathrm{~W} / \mathrm{cm}^{2}$.

\section{III (b) Angular distribution}

For planar targets we also measured the angular distribution of $\mathrm{x}$-ray yield. All yield measurements with the PCD array, described above; were recorded at target normal where the yield is expected to reach a maximum. To ease comparison with other reported work, we report the $x$-ray yield in this work as the conversion fraction into $2 \pi \mathrm{sr}$ as if the angular distribution were isotropic and equal to the angular fluence measured at target normal. The angular fluence varies relative to target normal, and depends on target material, laser wavelength, laser pulse duration and other factors. Generally the yield is reduced away from target normal and can be fitted with a $\cos ^{\alpha} \theta$ distribution, where $\alpha \leq 1$, and the total conversion into $2 \pi$ sr is less than the fraction reported in this work. There may be reasons to place the lithography exposure system at a location other than target normal, for example, to mitigate against debris, which is also maximized at target normal. Thus an assessment of the angular distribution is important to ascertain any reduction in $x$-ray yield at other angles.

We carried out the angular distribution measurements using Fe or type 302 stainless steel targets at the optimized conditions for both wavelengths. We fitted all PCD detectors with $2 \mu \mathrm{m} \mathrm{Zn}$ filters which transmit the main 
X-ray sources for proximity lithography component of the Fe spectrum. The detectors were arranged in four angular positions in the plane of the laser beam spanning angles from $18^{\circ}$ to $75^{\circ}$ from the target normal. For each measurement we took several sets of shots. Between each set we rotated the $\mathrm{Zn}$ filters through the detectors, in order to eliminate effects due to variations in the filter transmissivities. Results from these measurements, displayed in Figure 7, will be discussed below.

\section{III (c) Xe gas puff}

Optimization of the gas puff target followed a different procedure than for the planar solid targets. To optimize the $x$-ray yield from the gas puff we varied the position of the laser focus and the relative timing between the : vầlve opening and the laser pulse. Following a set of empirical studies where these two parameters were systematically adjusted we found that the timing was the most important parameter. The gas pulse produced from the valve lasted for a duration of approximately $1 \mathrm{~ms}$. The variation of $\mathrm{x}$-ray yield with delay is caused by the variation in gas density emerging from the nozzle, which reached a broad maximum during the gas pulse. We expect $x$-ray yields to increase with increasing atomic density. No measurements as a function of gas pressure were attempted since the particular valve system used was operating at its maximum pressure limit of approximately $10 \mathrm{~atm}$.

\section{RESULTS}

\section{IV (a) Planar solid targets}

$X$-ray yields from all of the solid targets are summarized in Figure 8 where the optimized yield for each material at both wavelengths is compared. High $x$-ray yields using the longer wavelength emitters $(\sim 14 \AA)$ were obtained with $1.053 \mu \mathrm{m}$ laser drive wavelength, with the best examples of these being type 302 stainless steel and solid $\mathrm{Xe}$. Conversion efficiency of these targets was approximately $10 \% / 2 \pi$ sr at the target normal. Conversion efficiency for shorter wavelength emitters using $1.053 \mu \mathrm{m}$ was significantly less, dropping to less than $4 \% / 2 \pi \mathrm{sr}$ for $\mathrm{Zn}$ targets emitting around $10.5 \AA$. we observed a significant improvement in $x$-ray yield with $0.527 \mu \mathrm{m}$ light, where conversion efficiencies for all targets were around $12 \% / 2 \pi$ sr or better. For the range of shorter wavelength emitters including $\mathrm{Cu}$, brass and $\mathrm{Zn}$ this 
X-ray sources for proximity lithography

represents a factor of $3-4$ improvement in the conversion efficiency measured at target normal. Since the energy conversion efficiency for doubling the laser light frequency is expected to be around $80 \%{ }^{19}$, this result indicates that operation at $0.527 \mu \mathrm{m}$ will provide a substantial improvement in conversion of energy from the fundamental laser wavelength to $x$-rays in the $10-12 \AA$ band, using a frequency-doubled laser.

It is interesting to note that the conversion efficiency measured with 302 stainless steel was the highest of all the materials tested, and is significantly higher than for the pure Fe tape. This improvement is apparent at $1.053 \mu \mathrm{m}$ light, and becomes quite dramatic with $0.527 \mu \mathrm{m}$ light, where the optimum conversion exceeds $16 \%$ for type 302 stainless steel.

\section{$X$-ray spectra}

A catalogue of spectra for all of the materials tested, and at both laser wavelengths is displayed in Figures 9 and 10. Also identified on the spectra are integral curves depicting the integrated conversion fraction through the range of emission wavelengths extending from short to long wavelngths.

All of the Xe spectra exhibit a bi-lobed distribution of emission with a main component emitting at wavelengths from $10-15 \AA$, and second component in the $17-20 \AA$. This latter component, comprising about 20 $30 \%$ of the emitted energy was also included in our conversion measurements, although this component is of little utility for lithography applications. Excluding this component (i.e. excluding wavelengths $>16 \AA$ ) the Xe conversion measured with 1.053 light is less than $10 \%$, but still comparable to the type 302 stainless steel conversion. With $0.527 \mu \mathrm{m}$ light the Xe spectrum becomes harder, shifting to shorter wavelengths, and the total conversion improves to around $12 \%$.

The improvement in yield obtained with type 302 stainless steel as compared with pure Fe targets is encouraging and supports the idea that $\mathrm{x}$-ray yield can be improved by mixing several elements of similar atomic number to fill out the emission spectrum. This is demonstrated most clearly in Figure 10 (a) which shows the dense spectrum of stainless steel as compared with the pure Fe spectrum displayed in Figure 10 (b). Stainless steel is an alloy comprised mainly of several transition metals with atomic numbers from $Z=$ 
$X$-ray sources for proximity lithography 24 through $\mathrm{Z}=28$ (the chemical composition of type 302 is approximately: $\mathrm{Fe}$, $70 \% ; \mathrm{Cr}, 18 \% ; \mathrm{Ni}, 9 \%$; and $\mathrm{Mn}, 2 \%$ ). The increased yield from the alloy occurs because the strongly emitting lines characteristic of each element are optically thick, or nearly so in the high density plasmas produced with solid targets; thus, the reduced concentration of $\mathrm{Fe}$ found in the stainless steel plasma as compared with that produced from pure Fe targets does not lead to a noticeable reduction in the intensity of the characteristic Fe spectral components, while the other alloyed elements in stainless steel provide emission features that fill in the gaps in the spectrum.

\section{Pulse energy dependence}

- An important characteristic of all of the conversion measurements from planar targets reported in this work is an increasing $x$-ray yield with pulse energy. For all materials we observed the conversion efficiency to increase montonically from near zero at low pulse energies, and increase to a saturation value before leveling off. Within the energy range available there was no evidence of a regime where conversion fraction decreased with increasing pulse energy. The saturation value varied with the target material and the laser wavelength. Examples of the energy dependence of the conversion and the saturation behaviour for $\mathrm{Cu}$ and type 302 stainless steel are shown in Figures 11 (a) and (b). The saturation level for efficient conversion with type 302 stainless steel (median emission wavelength at 15 $\AA$ ) is evidently lower than for Cu (median emission wavlength at $11.5 \AA$ ); saturation appears to be reached around $5-10 \mathrm{~J}$ for type 302 stainless steel. In the case of $\mathrm{Cu}$ it is not clear that the dependence of $\mathrm{x}$-ray conversion efficiency with energy reached a final saturation level at the maximum laser pulse energies available in these experiments. Correlated with the dependence of conversion efficiency on pulse energy was a clear shift in the x-ray spectrum for any given target to shorter wavelengths (harder photons) with increasing pulse energy. This is expected from the fact that increasing pulse energies produce higher intensities and drive hotter plasmas.

These pulse energy dependences are most easily understood in light of previous $0.5 \mathrm{~ns}$ pulse duration work by Chaker et al. ${ }^{14}$, in which conversion into $\mathrm{keV} \mathrm{x}$-rays from $\mathrm{Cu}$ targets was observed to drop abruptly below intensities of around $5 \times 10^{12} \mathrm{~W} / \mathrm{cm}^{2}$ for $1.06 \mu \mathrm{m}$ laser light. Optimum 
X-ray sources for proximity lithography conversion efficiencies for $\mathrm{Cu}$ measured in this work are comparable to the values reported by Chaker et al. As noted above our procedure for optimizing the conversion by scanning the focus automatically places the irradiance near this saturation intensity and not necessarily at the best focus. Consequently the measurements at decreasing pulse energy will produce lower than optimum intensities, and therefore produce lower x-ray yields. An implication of this interpretation is that it may be possible to attain high yields at lower pulse energies using a faster focusing lens (say $\mathrm{f} / 4$ instead of $\mathrm{f} / 13$ ), which will produce the needed intensity. However, we stress that achieving $10^{13} \mathrm{~W} / \mathrm{cm}^{2}$ is necessary but may not be sufficient to achieve high yields (with long pulses)-this possibility needs to be explored experimentally. . In our research, no attempts were made to exploit this method of obtaining high conversion efficiency at lower pulse energies.

\section{Laser drive wavelength dependence}

As a general rule the conversion fraction (laser energy to $x$-ray energy) into $2 \pi \mathrm{sr}$ is higher with $0.527 \mu \mathrm{m}$ laser light as compared with $1.053 \mu \mathrm{m}$ laser light. The effect is most accentuated for the short wavelength (10 - $12 \AA)$ emitters ( $\mathrm{Cu}, \mathrm{Zn}$, and brass) where the conversion fraction improves by a factor of $3-4$ times over the $1.053 \mu \mathrm{m}$ result. This dramatic improvement in conversion for the shorter wavelength emitters using frequency doubled laser light more than compensates for losses introduced by converting the fundamental to the second harmonic, and provides a means to obtain high $\mathrm{x}$ ray yields at a range of desired wavelengths spanning $10.5 \AA(\mathrm{Zn})$ through 15 $\AA$ (302 stainless steel) with a single laser driver.

Similar to spectral shifts that we observed with increasing pulse energy, we also observed a clear shift of the spectra of the various target types to shorter wavelengths when the drive wavelength was changed from $1.053 \mu \mathrm{m}$ to $0.527 \mu \mathrm{m}$. This spectral dependence is consistent with the improved coupling of the laser light into plasma heating at higher densities, and with the improved conversion. 
X-ray sources for proximity lithography

\section{Angular distribution}

The angular distributions measured for both drive wavelengths irradiating Fe or type 302 stainless steel targets are displayed in Figure 7. Fits to a $\cos ^{\alpha} \theta$ distribution yielded $\alpha \sim 0.2$ for $1.053 \mu \mathrm{m}$ irradiation and $\alpha \sim 0.6$ for $0.53 \mu \mathrm{m}$ irradiation. Neither of these angular distributions are Lambertian ( $\alpha$ $=1$ ). In the case of $1.053 \mu \mathrm{m}$ the emission is very close to being isotropic, such that at angles of $60^{\circ}$ to $70^{\circ}$ from the target normal the observed yield remains at $80 \%$ or more of the peak yield at target normal. At $0.53 \mu \mathrm{m}$ the emission is closer to Lambertian, with the yield reduced to $1 / 2$ of the peak at angles $>65^{\circ}$ off target normal. The difference in angular distribution reflects the difference in laser light coupling between the two wavelengths. The shorter wavelength couples much more efficiently into higher density plasma layers which are optically thick and situated closer to the target plane, thus producing a physical situation closer to that of a planar optically thick Lambertian surface emitter.

\section{IV (b) Xe gas puff}

We observed much lower $x$-ray yields from the Xe gas puff than from the solid Xe targets. The best conversion fraction we obtained with $1.053 \mu \mathrm{m}$ irradiation, was around $3 \%$ into $2 \pi \mathrm{sr}$; with $0.527 \mu \mathrm{m}$ light the conversion was substantially poorer, around $0.5 \% /(2 \pi \mathrm{sr})$. The poorer conversions obtained with the gas targets originates from the fact that these targets are at much lower densities than solids, such that the laser energy is not efficiently absorbed in the plasma. The $10 \mathrm{~atm}$ gas puff source produces an atomic density around $10^{19} \mathrm{~cm}^{-3}$ in the reservoir which is at least 3 orders of magnitude lower than solid densities; at the jet orifice where the plasma is produced maximum atom densities are probably lower. The $x$-ray pinhole images of the plasmas produced with this source (Figure 12) show that the laser generates an extended column of plasma with a length of approximately $1 \mathrm{~mm}$ and cross-sectional diameter of $100-300 \mu \mathrm{m}$. This column extended some distance into the jet orifice where it was not visible.

It is clear that the gas density was too low to absorb the laser energy significantly. The rather short $\mathrm{x}$-ray pulses produced with the gas target as compared with the solid Xe target provide evidence of this poor absorption. 
X-ray sources for proximity lithography

In Figure 13 we compare pulses produced by the gas puff irradiated with both wavelengths as well as a pulse produced with a cryogenic Xe target irradiated with $1.053 \mu \mathrm{m}$ light. In the gas puff $\mathrm{x}$-ray emission is strong only near the beginning of the pulse and rapidly diminishes before the end of the laser drive pulse to produce a short $\mathrm{x}$-ray pulse. We interpret this behavior to be caused by quick penetration of the laser through the underdense gas and beyond, where the laser energy was lost and not converted to $x$-rays. The higher conversion with $1.053 \mu \mathrm{m}$ reflects the fact that the longer wavelength is more efficiently absorbed at this gas density. This is a consequence of the expected inverse bremsstrahlung absorption process in underdense plasma, for which the absorption coefficient ${ }^{28}$ scales as $\lambda^{2}$. Thus, at $0.527 \mu \mathrm{m}$ the absorption coefficient is a factor of 4 weaker largely accounting for the 6-fold smaller x-ray yield; this situation is also consistent with the shorter x-ray pulses produced with $0.527 \mu \mathrm{m}$ light.

Self-absorption by cold Xe gas anywhere between the $x$-ray source and the detector (or lithography system) turns out to be a significant effect with this type of gas puff source. Cold Xe has an L-shell absorption edge situated around $18 \AA$; below this wavelength $\mathrm{x}$-rays are absorbed significantly more than above with an absorption coefficient in proportion to the amount of intervening gas. The spectral modifications due to this effect are clearly demonstrated in Figure 14. X-rays in the $10-15 \AA$ band are substantially absorbed by about $300 \mu \mathrm{m}$ of cold Xe at the densities (around $10^{19} \mathrm{~cm}^{-3}$ ) produced at the nozzle orifice. Absorption from a higher density gas puff will be proportionately more, unless the column of gas is highly confined or collimated.

\section{CONCLUSIONS}

The intended operating $x$-ray wavelength of a proximity lithography system will be determined by a number of considerations which are beyond the scope of the present study. For most situations $x$-ray wavelengths within the range from $10 \AA$ through $15 \AA$ may be used. The materials selected in this study embrace this wavelength region comprehensively, as summarized in Figure 15. These results demonstrate a significant degree of flexibility in delivering $x$-ray energy within a desired wavelength band using a laserproduced plasma. 
X-ray sources for proximity lithography

$X$-ray conversion from all targets increased with increasing laser pulse energy from small values at low pulse energies $(<5 \mathrm{~J})$. A minimum pulse energy of approximately $5-10 \mathrm{~J}$ was necessary to approach the yields close to the optimum. Above approximately $10 \mathrm{~J}$ the yield versus pulse energy curve begins to saturate. This behaviour is consistent with the observed saturation of conversion with laser intensity observed by Chaker et al. ${ }^{14}$ using $0.5 \mathrm{~ns}$ pulses, thus indicating that the $10 \mathrm{~ns}$ plasma behaves similarly in this pulse energy range. At optimum conditions, the average intensity illuminating the plasma was approximately $5 \times 10^{12} \mathrm{~W} / \mathrm{cm}^{2}$ for $1.053 \mu \mathrm{m}$ light, and $10^{13} \mathrm{~W} / \mathrm{cm}^{2}$ for $0.527 \mu \mathrm{m}$ light. For both wavelengths the source size at optimum conversion was approximately $250-300 \mu \mathrm{m}$ in diameter.

Both cryogenic Xe and the Xe gas puff targets offer the attractive possibility of building a reduced debris source. The Xe spectrum contains two main components, with a longer wavelength portion occupying the $17-20 \AA$. For lithography $75 \%$ - $80 \%$ of the energy is emitted in a 10 - $14 \AA$ band, while 20 $25 \%$ is emtted in the $17-20 \AA$ band. At $0.527 \mu \mathrm{m}$ the $10-14 \AA$ portion of the spectrum is significantly harder than with $1.053 \mu \mathrm{m}$. While the Xe gas puff offers potentially the most attractive source of this type, the conversion efficiency we measured with the $10 \mathrm{~atm} X \mathrm{X}$ gas puff was rather low, attaining about $3 \% / 2 \pi$ sr at best using $1.053 \mu \mathrm{m}$ laser light. This level,is too low for current proximity lithography needs. Furthermore, it is also evident that cold gas absorption significantly attenuates $x$-rays at wavelengths less than $18 \AA$. These factors indicate that the realization of an effective $X e$ gas puff source will require a substantial effort aimed at increasing the gas pressure and mitigating cold gas absorption effects. Solid Xe provides $\mathrm{x}$-ray yields comparable to or better than other solid targets, at both drive wavelengths investigated. In the format of cryogenic pellets, frozen Xe offers the potential for producing a reduced debris source, with yields comparable to solid target yields, and without the finite density and gas absorption problems that arise with a Xe gas puff.

The best yields were attained with type 302 stainless steel targets, which consist of an alloy containing $\mathrm{Cr}, \mathrm{Ni}$ and $\mathrm{Mn}$ as the main components in addition to $\mathrm{Fe}$. This result indicates the possibility for improving $\mathrm{x}$-ray yields by designing mixtures of elements that emit in the desired wavelength band. The high yields of $X e$ are produced for a similar reason, namely that the 
X-ray sources for proximity lithography much more complicated electronic structure of the Xe $\mathrm{M}$-shell provides many more emission lines to fill in the spectral band than the simpler L-shell emitters.

The $x$-ray yields produced with the long pulse laser driver used in these experiments matched yields measured previously with shorter (ns-duration) pulses. The duration of the $x$-ray pulse matched the duration of the laser pulse indicating that, at least in the 12 - $14 \mathrm{~ns}$ range, the long pulse duration does not degrade the conversion efficiency. A frequency-doubled Nd:glass laser driver can be used to produce a source with median wavelength anywhere from $10.5 \AA$ to $15 \AA$ at yields that meet the needs of proximity lithography down to $0.12 \mu \mathrm{m}$ feature size requirements.

\section{ACKNOWLEDGEMENTS}

We acknowledge technical support from Jim Wintemute, Jim Cox, Ken Haney and Joe Smith. This work was performed under the auspices of the U.S. Department of Energy by Lawrence Livermore National Laboratory under contract W-7405-ENG-48 and was supported by the U.S. Department of Defense Advanced Research Projects Agency under ARPA Order No. A251. 
X-ray sources for proximity lithography

\section{REFERENCES}

1. K. M. Gilbert, J. P. Anthes, M. A. Gusinow, M. A. Palmer, R. R. Whitlock and D. J. Nagel, "X-ray yields of plasmas heated by 8-nsec neodymium laser pulses,"J. Appl. Phys. 51, 1449-1451 (1980).

2. B. Yaakobi, P. Bourke, Y. Conturie, J. Delettrez, J. M. Forsyth, R. D. Frankel, L. M. Goldman, R. L. McCrory, W. Seka, J. M. Soures, A. J. Burek and $R$. E. Deslattes, "High $x$-ray conversion efficiency with target irradiation by a frequency tripled Nd:glass laser,"Opt. Commun. 38, 196-200 (1981).

3. H. Nishimura, F. Matsuoka, M. Yagi, K. Yamada, S. Nakai, G. H. McCall añd C. Yamanaka, "Radiation conversion and related ablation behavior of a gold-foil target irradiated by $0.35,0.53,1.06$, and $10.6 \mu \mathrm{m}$ lasers,"Phys. Fluids 26, 1688-1692 (1983).

4. D. L. Matthews, E. M. Campbell, N. M. Ceglio, G. Hermes, R. Kauffman, L. Koppel, R. Lee, K. Manes, V. Rupert, V. W. Slivinsky, R. Turner and F. Ze, "Characterization of laser-produced plasma $x$-ray sources for use in $x$-ray radiography,"J. Appl. Phys. 54, 4260-4268 (1983).

5. W. C. Mead, E. M. Campbell, K. G. Estabrook, R. E. Turner, W. L. Kruer, P. H. Y. Lee, B. Pruett, V. C. Rupert, K. G. Tirsell, G. L. Stradling, F. Ze, C. E. Max, M. D. Rosen and B. F. Lasinski, "Laser irradiation of disk targets at 0.53 $\mu \mathrm{m}$ wavelength,"Phys. Fluids 26, 2316-2331 (1983).

6. P. Alaterre, H. Pépin, R. Fabbro and B. Faral, "X-ray conversion as a funtion of atomic number for $0.26-\mu \mathrm{m}$-laser-irradiated targets,"Phys. Rev. A34, 4184-4194 (1986).

7. T. Mochizuki, T. Yabe, K. Okada, M. Hamada, N. Ikeda, S. Kiyokawa and C. Yamanaka, "Atomic-number dependence of soft $\mathrm{x}$-ray emission from various targets irradiated by a $0.53-\mu \mathrm{m}$-wavelength laser,"Phys. Rev. A33, 525539 (1986).

8. R. Popil, P. D. Gupta, R. Fedosejevs and A. A. Offenberger, "Measurement of $\mathrm{KrF}$-laser-plasmaa $\mathrm{x}$-ray radiation from targets with various atomic numbers,"Phys. Rev. A35, 3874-3882 (1987). 
X-ray sources for proximity lithography

9. K. Eidmann and W. Schwanda, "Conversion of laser light into soft $X$ rays with 3-ns and 30-ps laser pulses,"Laser and Particle Beams 9, 551-562 (1991).

10. J. N. Broughton and R. Fedosejevs, "Efficient keV x-ray generation from 50 mJ KrF laser plasmas,"Appl. Phys. Lett. 60, 1818-1821 (1992).

11. D. J. Nagel, M. C. Peckerar, R. R. Whitlock, J. R. Greig and R. E. Pechacek, "Submicrosecond x-ray lithography,"Electron. Lett. 14, 781-782 (1978).

12. B. Yaakobi, H. Kim, J. M. Soures, H. W. Deckman and J. Dunsmuir, "Submicron x-ray lithography using laser-produced plasma as a source,"Appl. . Phays. Lett. 43, 686-688 (1983).

13. H. Pépin, P. Alaterre, M. Chaker, R. Fabbro, B. Faral, I. Toubhans, D. J. Nagel and M. Peckerar, "X-ray sources for microlithography created by laser radiation at $\lambda=0.26 \mu \mathrm{m}, " J$. Vac. Sci. Technol. B5, 27-32 (1987).

14. M. Chaker, H. Pépin, V. Bareau, B. Lafontaine, I. Toubhans, R. Fabbro and B. Faral, "Laser plasma x-ray sources for microlithography,"J. Appl. Phys. 63, 892-899 (1988).

15. G. M. Davis, M. C. Gower, F. O'Neill and I. C. E. Turcu,'"Plasma x-ray source for lithography generated by a $\approx 30 \mathrm{~J}, 30 \mathrm{~ns} \mathrm{KrF}$ laser,"Appl. Phys. Lett. $53,1583-1585$ (1988).

16. M. Chaker, B. L. Fontaine, C. Y. Côté, J. C. Kieffer, H. Pépin, M. H. Talon, G. D. Enright and D. M. Villeneuve, "Laser plasma sources for proximity printing or projection x-ray lithography,"J. Vac. Sci. Technol. B10, 3239-3242 (1992).

17. M. Chaker, J. F. Pelletier and J. C. Kieffer. in Materials Aspects of X-ray Lithography (eds. G. K. Celler and J. R. Maldonado) 151-167 (Materials Research Society, San Francisco, CA, USA, 1993).

18. R. Kodama, T. Mochizuki, K. A. Tanaka and c. Yamanaka, "Enhancement of $\mathrm{keV} \mathrm{x}$-ray emission in laser-produced plasmas by a weak prepulse laser,"Appl. Phys. Lett. 50, 720-722 (1987). 
X-ray sources for proximity lithography 19. C. B. Dane, L. E. Zapata, W. A. Neuman, M. A. Norton and L. A. Hackel, "Design and Operation of a $150 \mathrm{~W}$ Near Diffraction-Limited Laser Amplifier with SBS Wavefront Correction,"IEEE J. Quant. Electron. 31, 148-163 (1995).

20. C. B. Dane, W. A. Neuman and L. A. Hackel, "High-Energy SBS Pulse Compression,"IEEE J. Quant. Electron. 30, 1907-1915 (1994).

21. H. Fiedorowicz, A. Bartnik, Z. Patron and P. Parys, "X-ray emission from laser-irradiated gas puff targets," Appl. Phys. Lett. 62, 1-3 (1993).

22. Princeton Instruments, Inc., 3660 Quakerbridge Rd., Trenton NJ 08619 USA

23̀. B. L. Henke, P. Lee, T. J. Tanaka, R. L. Shimabukuro and B. K. Fujikawa, "Low-energy $x$-ray interaction coefficients: Photoabsorption, Scattering and Reflection. E = $100-2000$ eV Z = 1-94,"At. Data Nucl. Data Tables 27, 1-144 (1982).

24. D. R. Kania, L. Pan, H. Korblum, P. Bell, O. L. Landen and P. Pianetta, "Soft x-ray detection with diamond photoconductive detectors,"Rev. Sci. Instrum. 61, 2765-2767 (1990).

25. D. R. Kania, H. Kornblum, B. A. Hammel, J. Seely, C. Brown, U. Feldman, G. Glendinning, P. Young, E. Hsieh, M. Hennesian, L. DaSilva, B. J. Macgowan, D. S. Montgomery, C. A. Back, R. Doyas, J. Edwards and R. W. Lee, "Characterization of an x-ray flux source for the production of high-energydensity plasmas,"Phys. Rev. A46, 7853-7868 (1992).

26. D. R. Kania, L. S. Pan, P. Bell, O. L. Landen, H. Kórnblum, P. Pianetta and M. D. Perry, "Absolute $x$-ray power measurements with subnanosecond time resolution using type IIa diamond photoconductors,"J. Appl. Phys. 68, 124-130 (1990).

27. Lebow Company, 5960 Mandarin Ave., Goleta, CA 93117 USA

28. T. W. Johnston and J. M. Dawson, "Correct values for high-frequency power absorption by inverse bremsstrahlung in plasmas,"Phys. Fluids 16, 722 (1973). 
X-ray sources for proximity lithography

\section{FIGURE CAPTIONS}

Figure 1. Experimental arrangement employed for solid target $\mathrm{x}$-ray yield measurements.

Figure 2. Experimental arrangement employed for gas puff $x$-ray yield measurements.

Figure 3. Sample oscilloscope traces of the laser pulse measured with a photodiode and an x-ray pulse measured with a PCD detector. Vertical scales and temporal offsets for both pulses are arbitrary, and were adjusted for purposes of comparison.

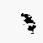

Figure 4. Variation of $x$-ray yield with focusing lens position for $1.053 \mu \mathrm{m}$ laser light; this procedure was used to optimize the yield for a given target type.

Figure 5. Variation of $x$-ray emitting plasma volume with focusing lens postion for $1.053 \mu \mathrm{m}$ laser light irradiating a solid Fe target. The upper part of the figure displays a sequence of pinhole photographs of the plasma $x$-ray emission taken at various lens positions (indicated on the individual frames). The lower figure displays the variation of plasma size with lens position measured from the pinhole photographs. Also shown for comparison is the beam size assuming a geometric $f / 13$ focal cone with best focus assumed to occur at the lens position producing the smallest plasma volume.

- Figure 6. Similar to Figure 5, except with $0.527 \mu \mathrm{m}$ laser light irradiating a type 302 stainless steel solid target.

Figure 7. Angular distribution of $x$-ray emission relative to target normal measured for $14 \AA$ emitters Fe or type 302 stainless steel at both drive wavelengths.

Figure 8. Optimized $\mathrm{x}$-ray yields measured for all solid targets and both drive wavelengths.

Figure 9. X-ray spectra measured for all solid targets using $1.053 \mu \mathrm{m}$ laser light. Spectral intensity is displayed on the arbitrary left hand scale; the wavelength integrated $x$-ray yield for each material can be measured against 
X-ray sources for proximity lithography

the right hand scale. Conversion fraction indicates the ratio of $x$-ray energy divided by incident laser energy. Target materials are (a) type 302 stainless steel; (b) $\mathrm{Fe}$; (c) Xe; (d) Cu; (e) brass; and, (f) Zn.

Figure 10. Same as for Figure 9, except using $0.527 \mu \mathrm{m}$ laser light.

Figure 11. Pulse energy dependence of $x$-ray yield for two target materials and a both drive wavelengths. Target materials are: (a) type 302 stainless steel; and, (b) $\mathrm{Cu}$.

Figure 12. X-ray emission volume observed with the Xe gas puff target irradiated with (a) $1.053 \mu \mathrm{m}$ laser light; and, (b) $0.527 \mu \mathrm{m}$ laser light.

$*$

Figure 13. X-ray pulses emitted from a Xe gas puff target irradiated with $1.053 \mu \mathrm{m}$ laser light and $0.527 \mu \mathrm{m}$ laser light, compared with emission pulse observed from a solid Xe target irradiated with $1.053 \mu \mathrm{m}$ laser light.

Figure 14. $X$-ray spectra emitted from a $X e$ gas puff target with varying amounts of cold Xe gas situated between the plasma column and the spectrograph. Cold Xe gas thicknesses were approximately (a) $600 \mu \mathrm{m}$; (b) 300 $\mu \mathrm{m}$; and, (c) $0 \mu \mathrm{m}$.

Figure 15. Emission wavelengths determined from the spectra measured for all the solid elements at both laser drive wavelengths. The bar end points indicate wavelengths spanning $10 \%$ to $90 \%$ of the wavelength-integrated emission (i.e. containing $80 \%$ of the emission). The points within the bars indicate the median emission wavelengths ( $50 \%$ point on the integral curve) for each material. *In the special case of $\mathrm{Xe}$, this evaluation was restricted to wavelengths less than $16 \AA$, which eliminates the long wavelength emission component $(\sim 18 \AA)$ from the weighting process. 


\section{TABLES}

\begin{tabular}{|c|c|c|c|}
\hline $\begin{array}{r}\text { Filter } \\
\text { material }\end{array}$ & $\begin{array}{c}\text { Thickness } \\
(\mu \mathrm{m})\end{array}$ & $\begin{array}{c}\text { Substrate } \\
\text { bavelength } \\
\text { band } \\
(\AA)\end{array}$ \\
\hline \hline $\mathrm{Al}$ & 10.6 & - & $8-11$ \\
$\mathrm{Zn}$ & 2.0 & $1000 \AA$ parylene & $12-15$ \\
$\mathrm{Co}$ & 1.0 & - & $16-22$ \\
$\mathrm{Al}$ & 0.56 & $1.5 \mu \mathrm{m}$ mylar & $8-17$ \\
\hline
\end{tabular}

Table 1. Filter materials and thickness used for $\mathrm{x}$-ray yield measurements with the PCD detectors. 


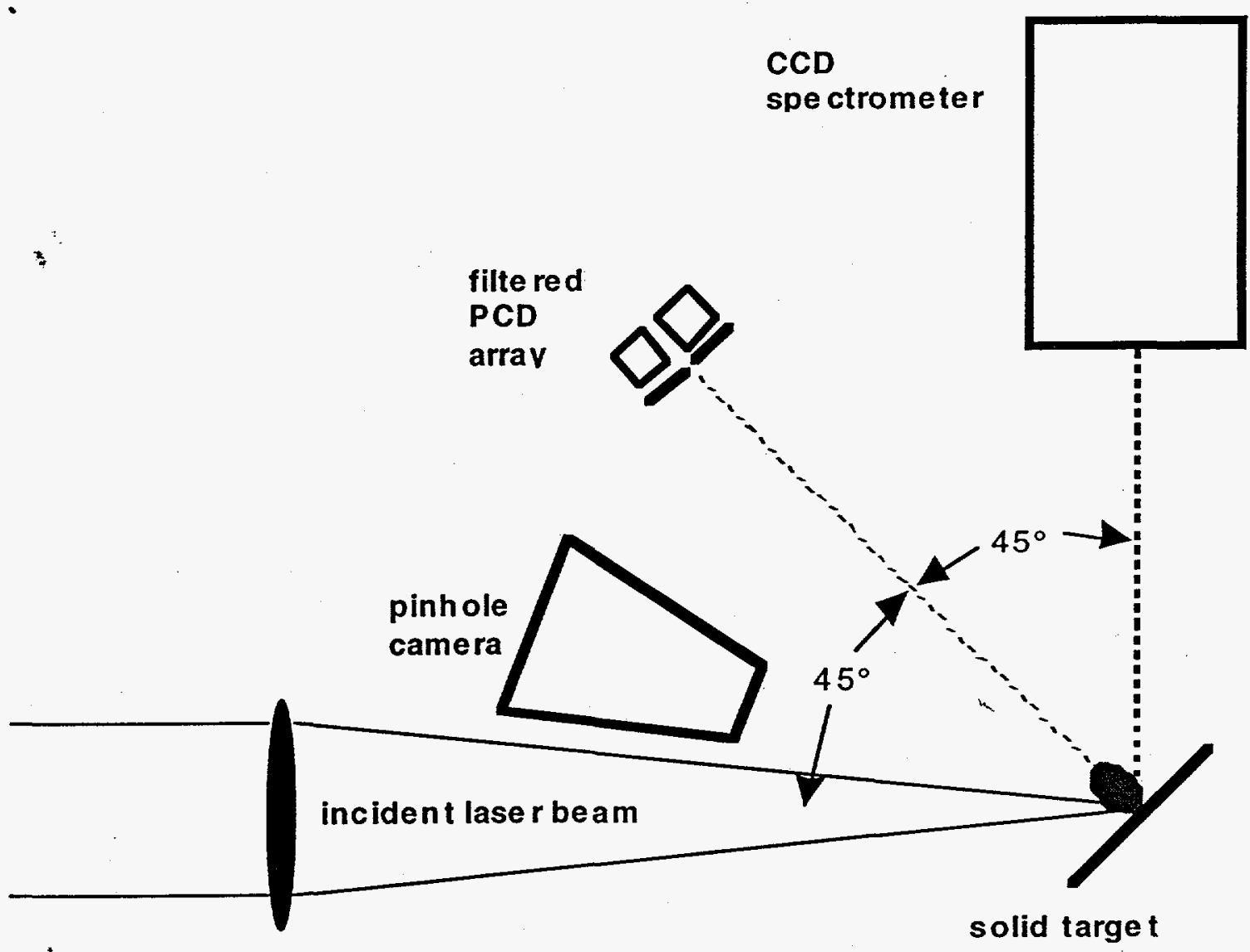

Figure 1 
X-ray sources for proximity lithography
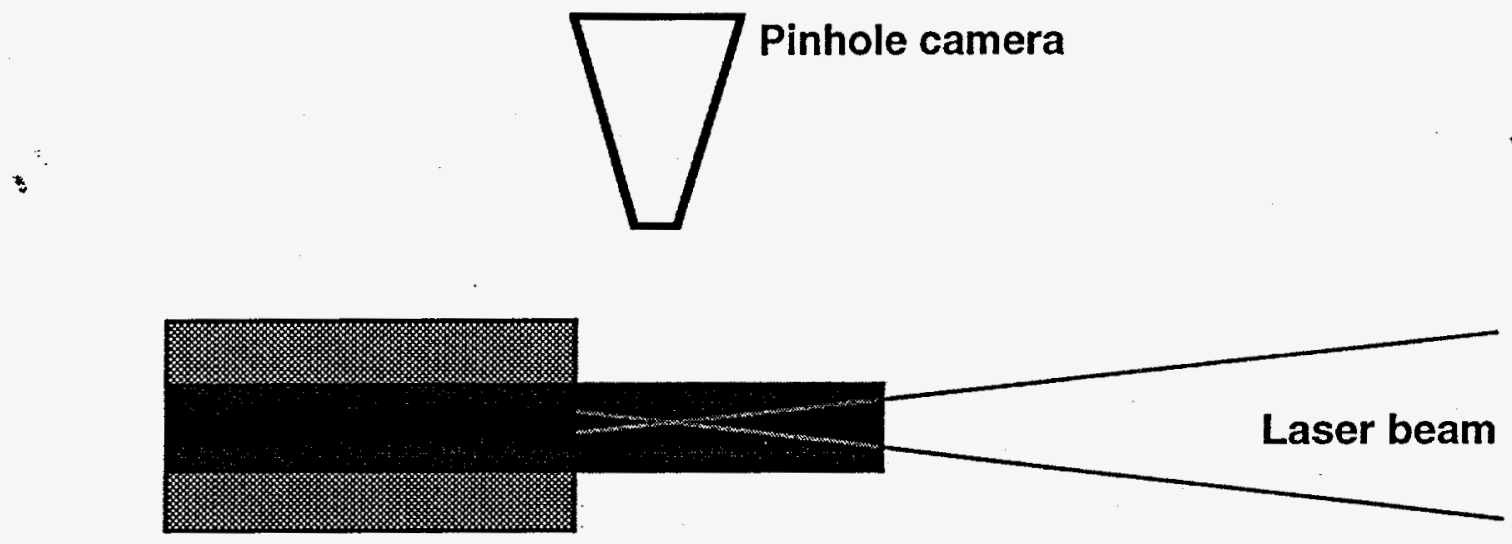

Nozzle $-10 \mathrm{~atm}$ pressure

Figure 2 
X-ray sources for proximity lithography

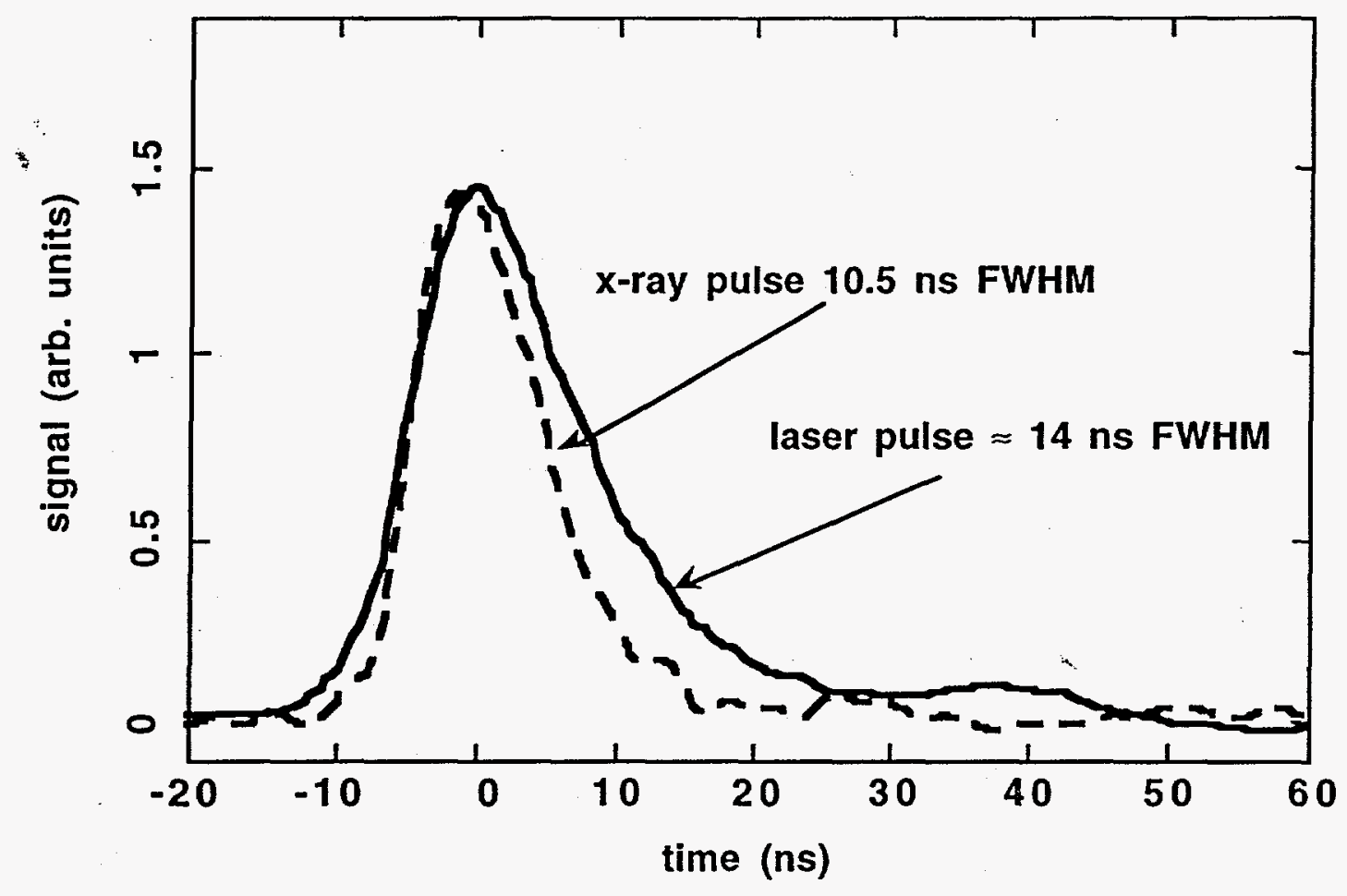

Figure 3 
X-ray sources for proximity lithography

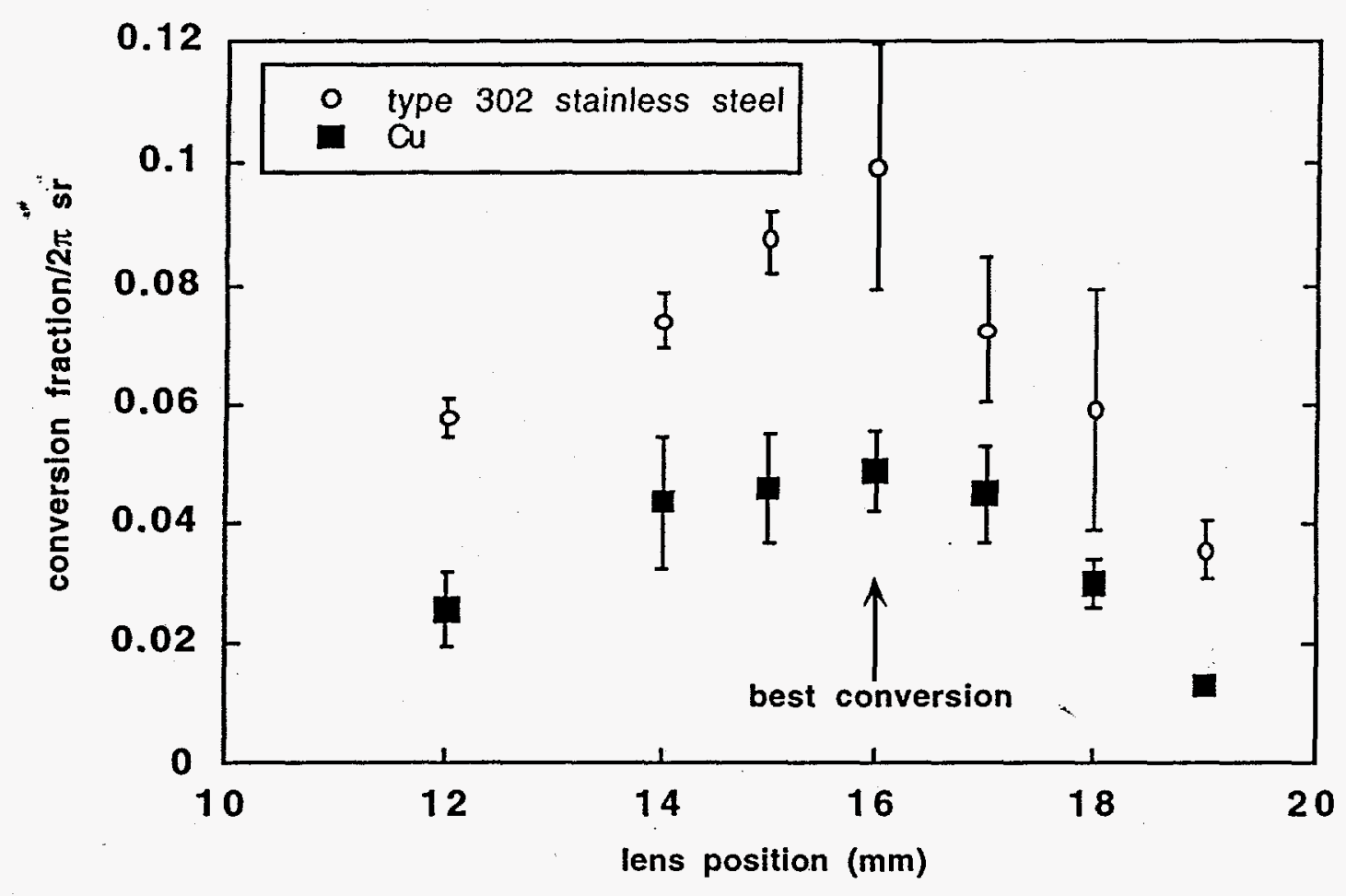

Figure 4 
X-ray sources for proximity lithography
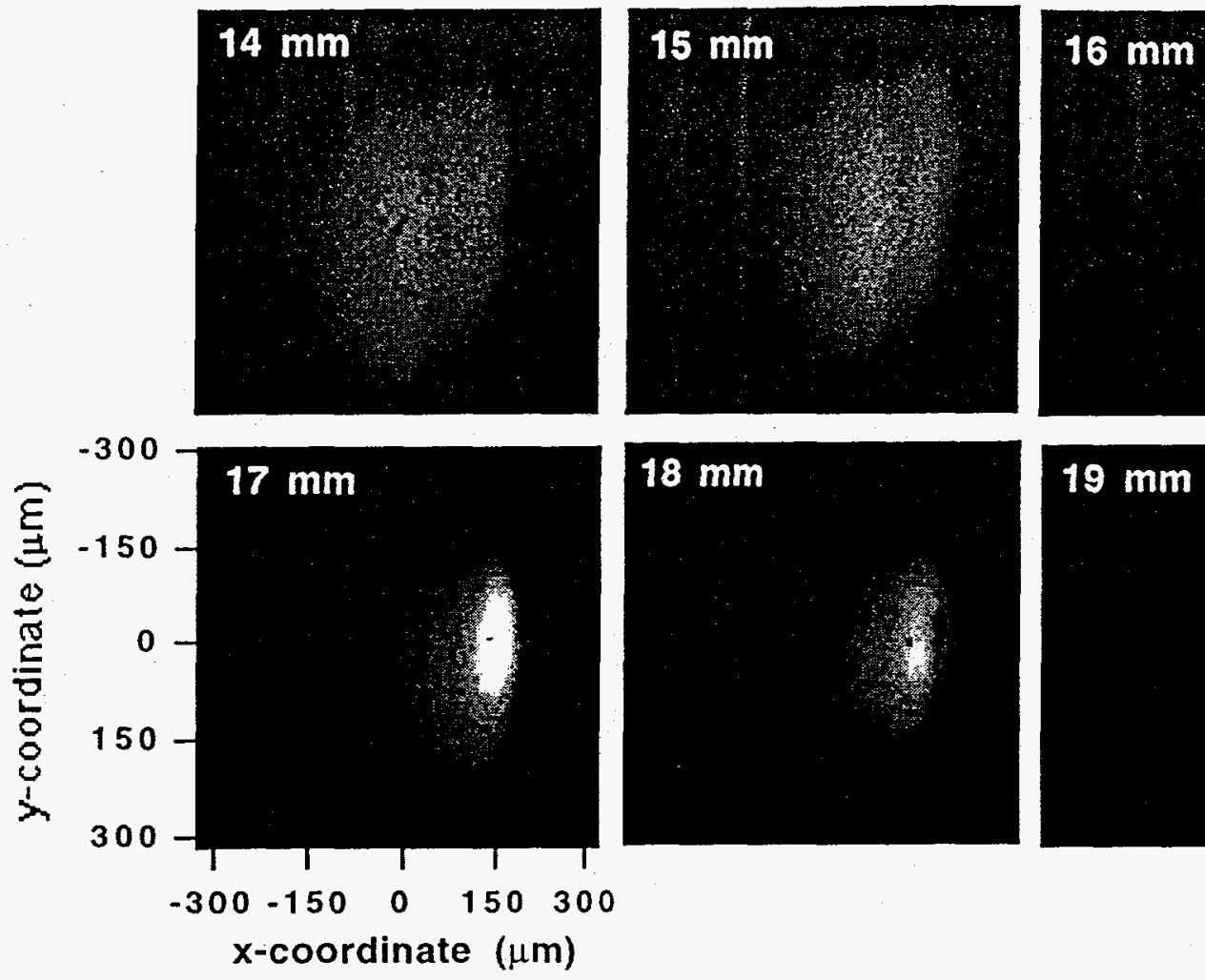

\section{$18 \mathrm{~mm}$}

\section{$19 \mathrm{~mm}$}
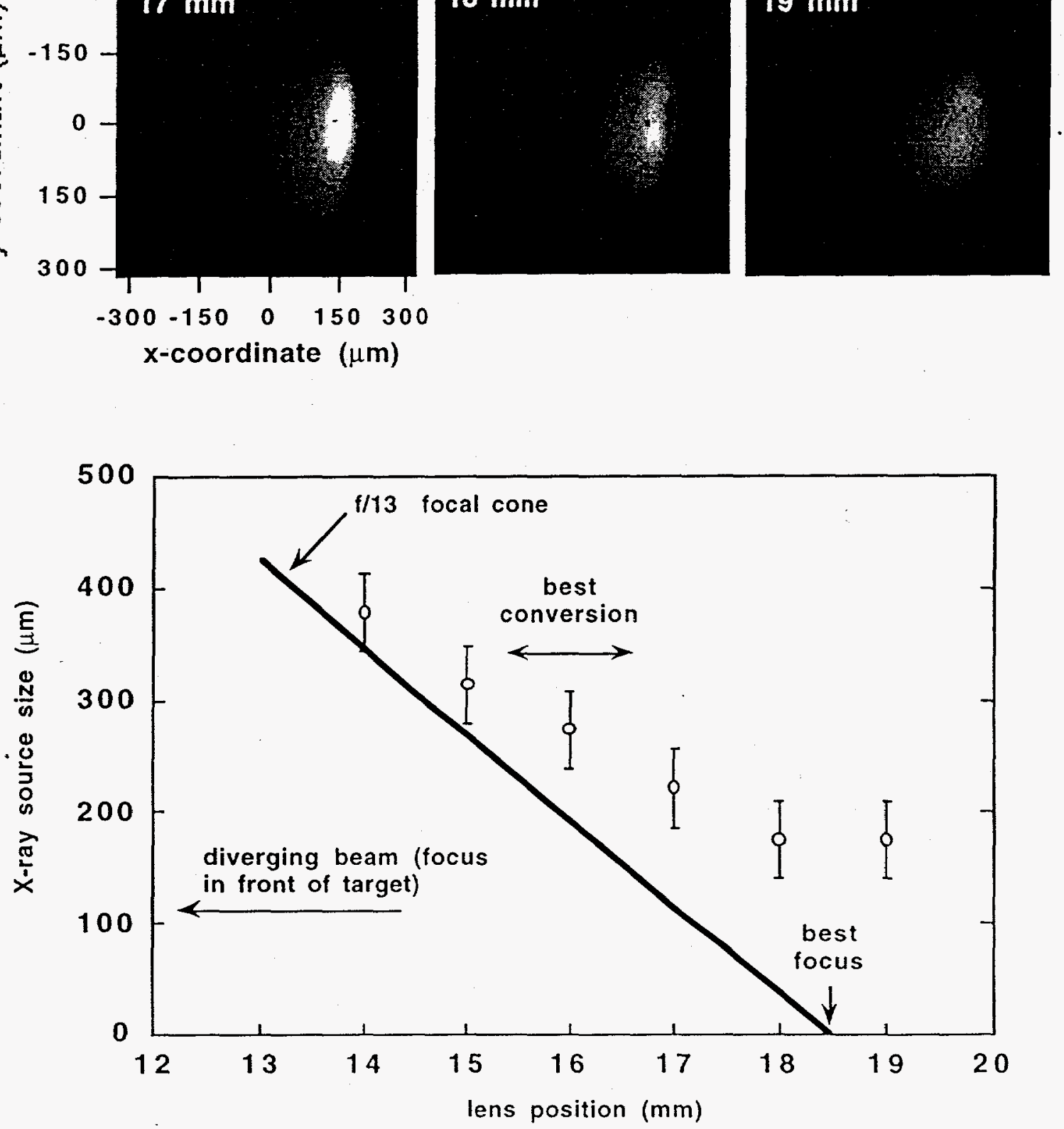

Figure 5 

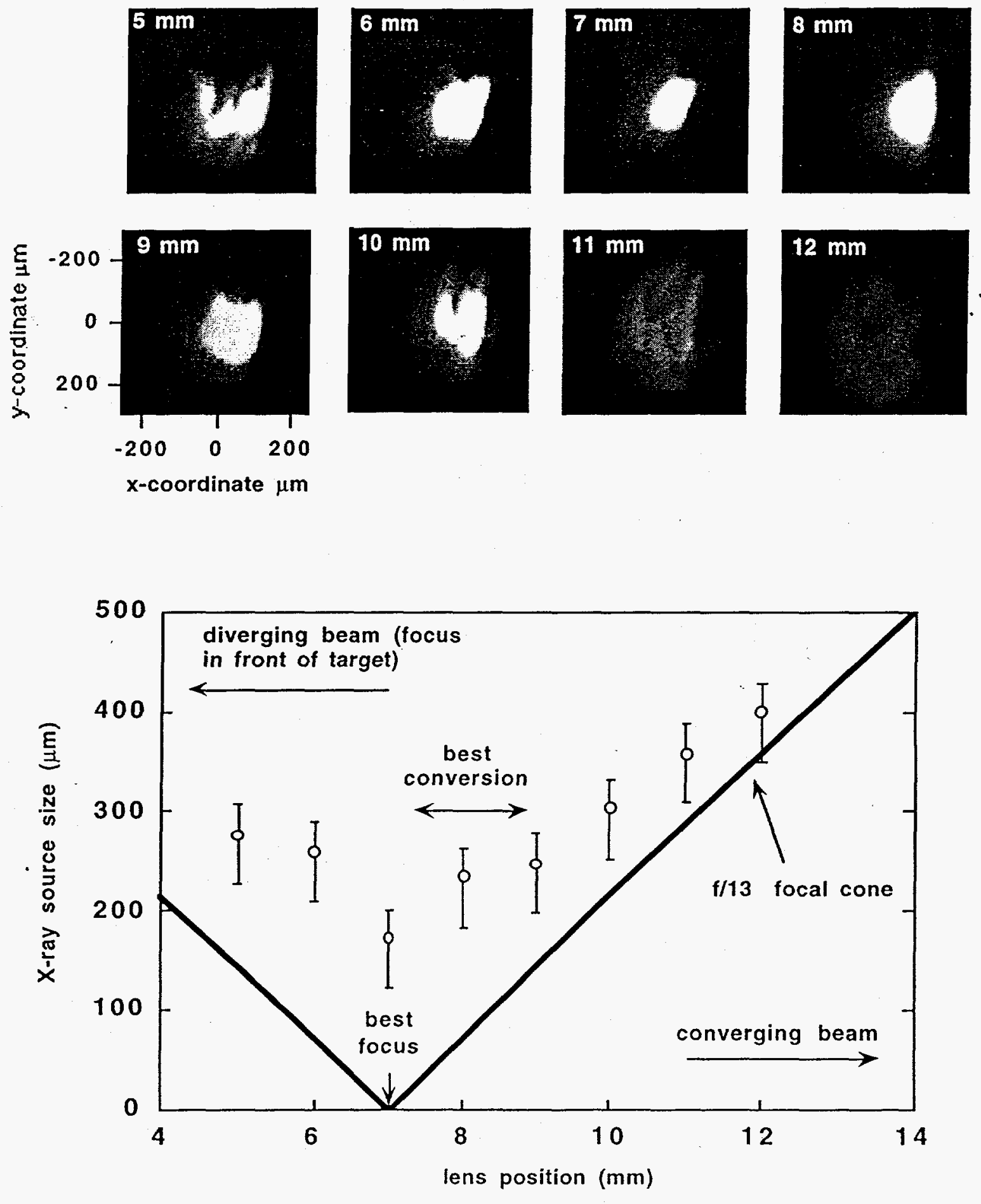

Figure 6 


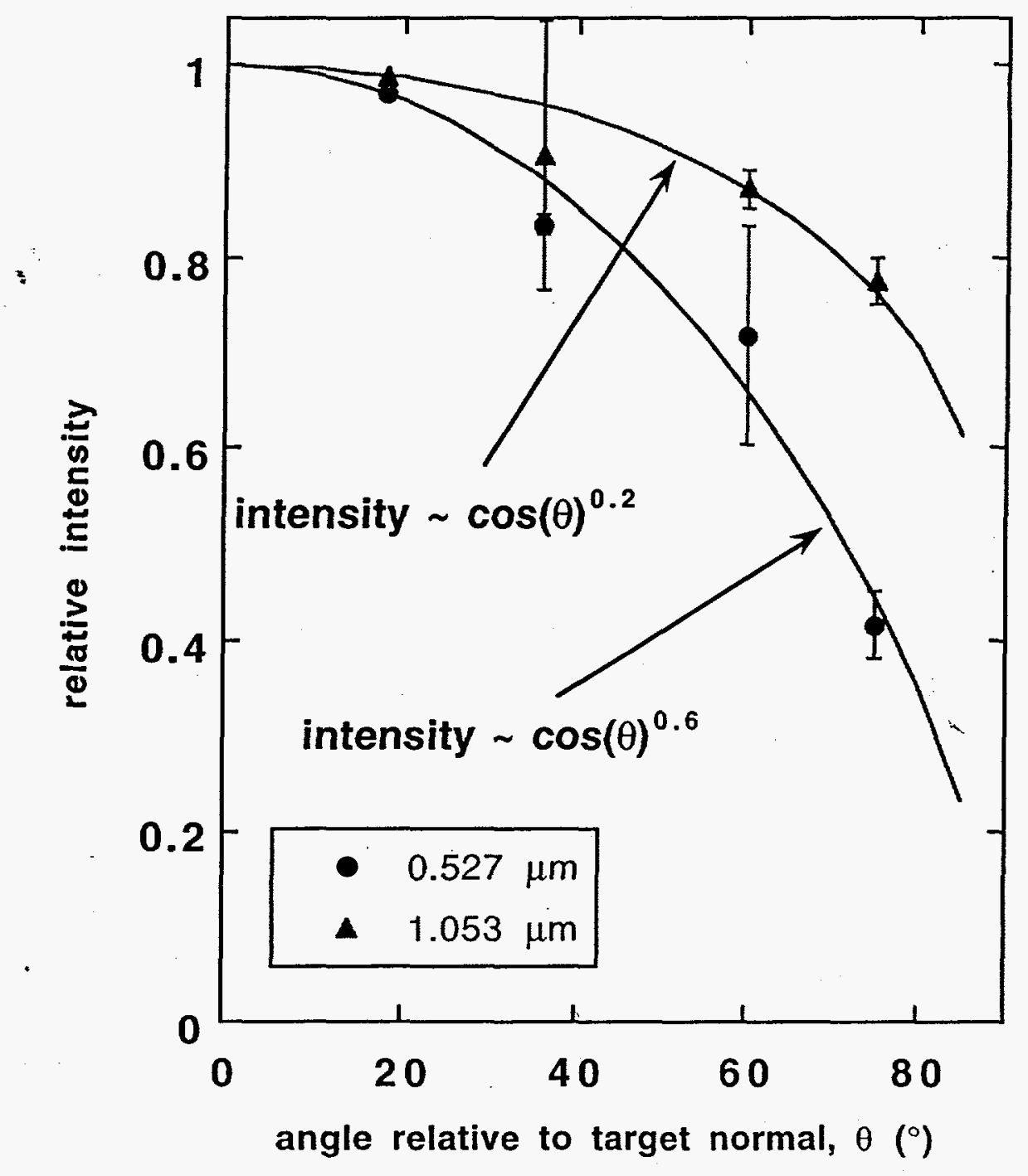

Figure 7 


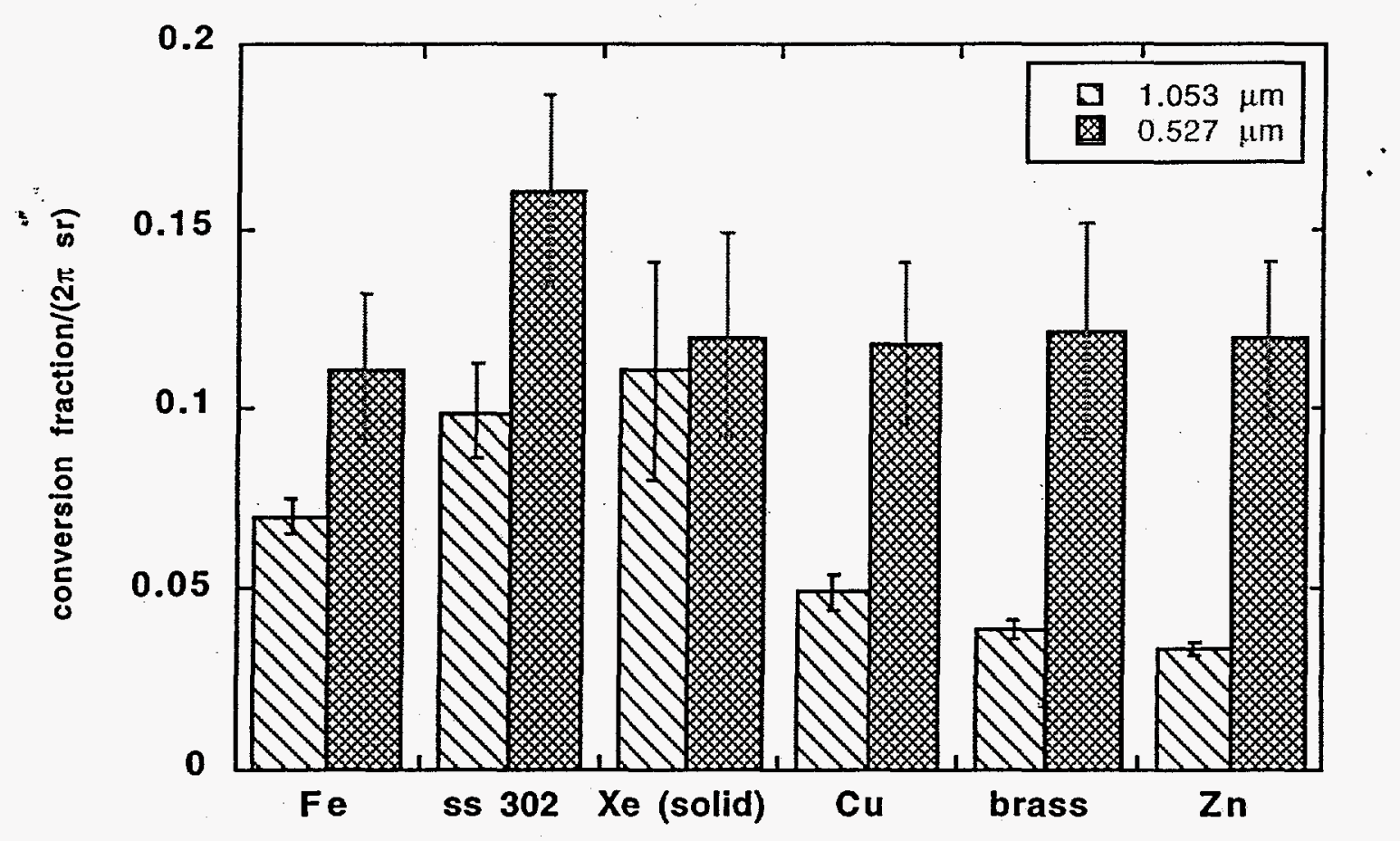

Figure 8 
X-ray sources for proximity lithography

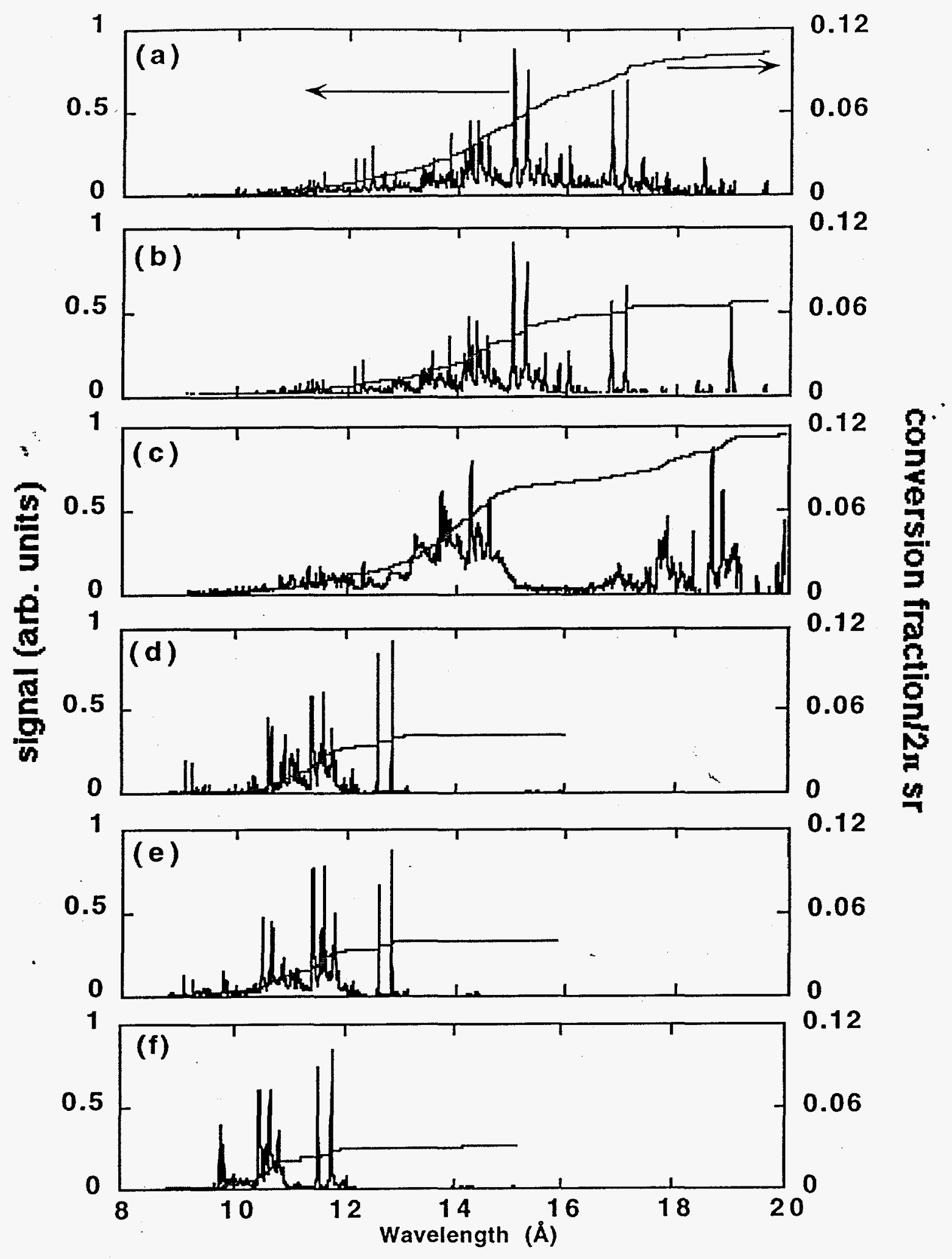

Figure 9 
X-ray sources for proximity lithography

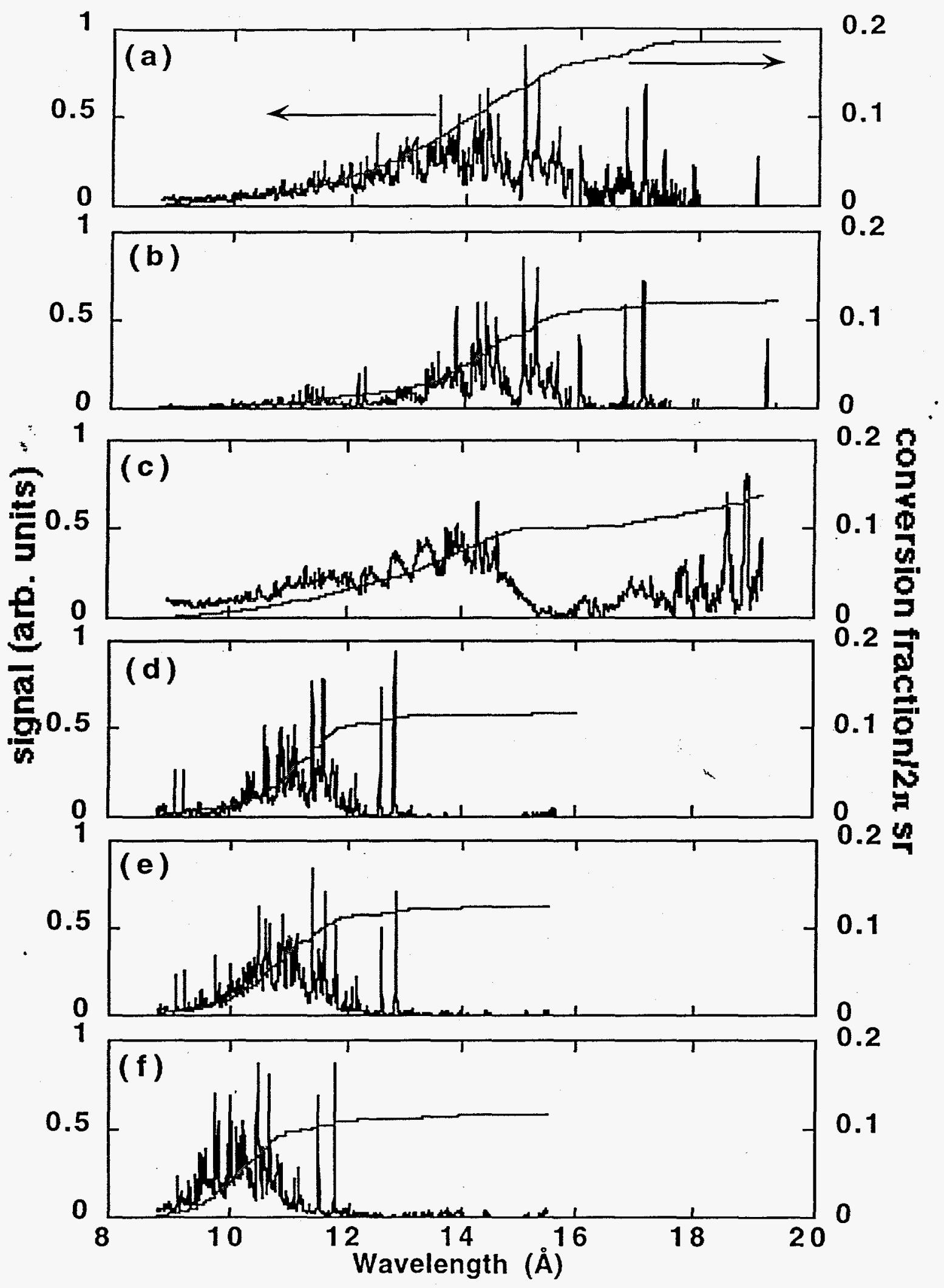

Figure 10 
X-ray sources for proximity lithography
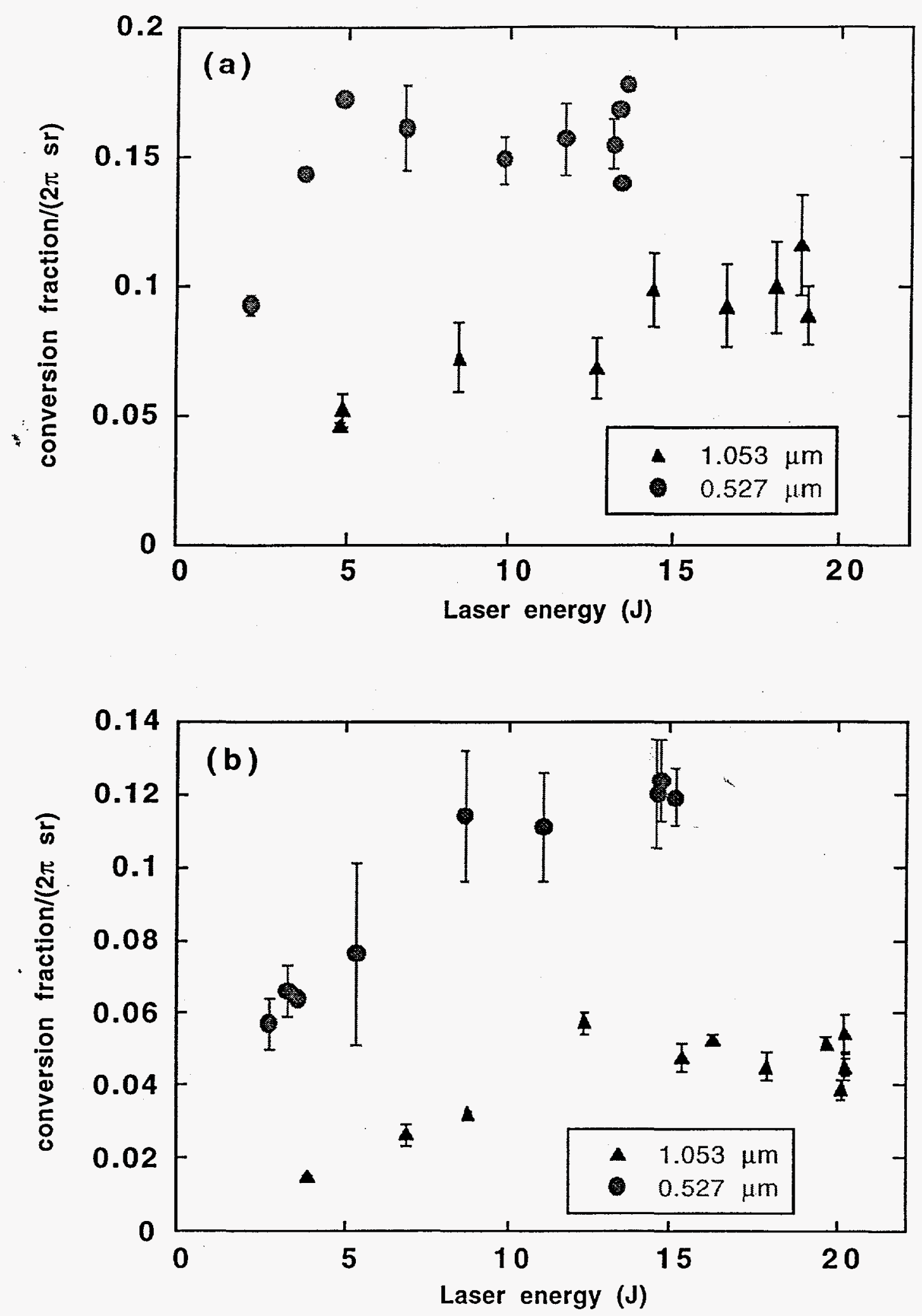

Figure 11 
X-ray sources for proximity lithography
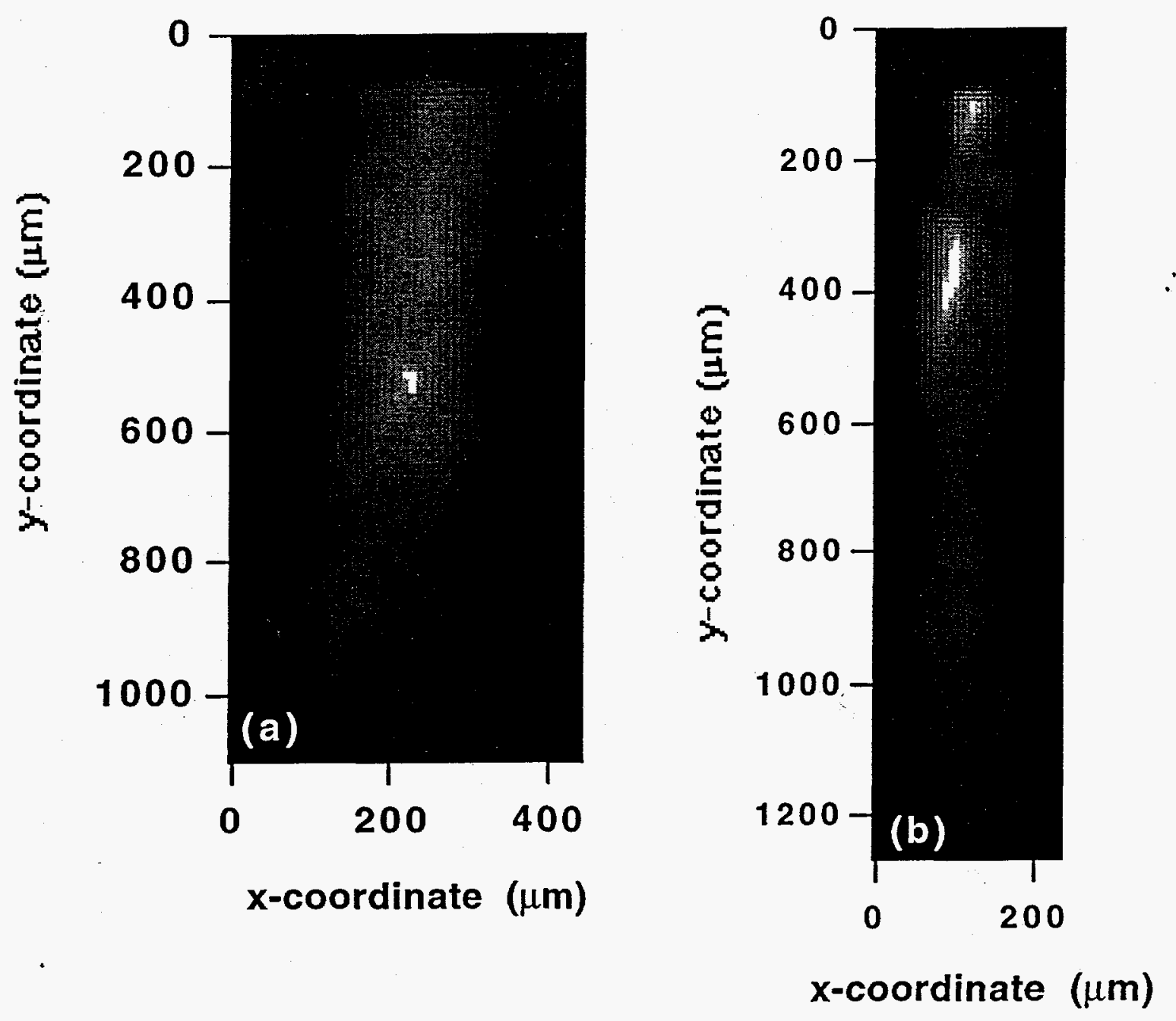

Figure 12 
X-ray sources for proximity lithography

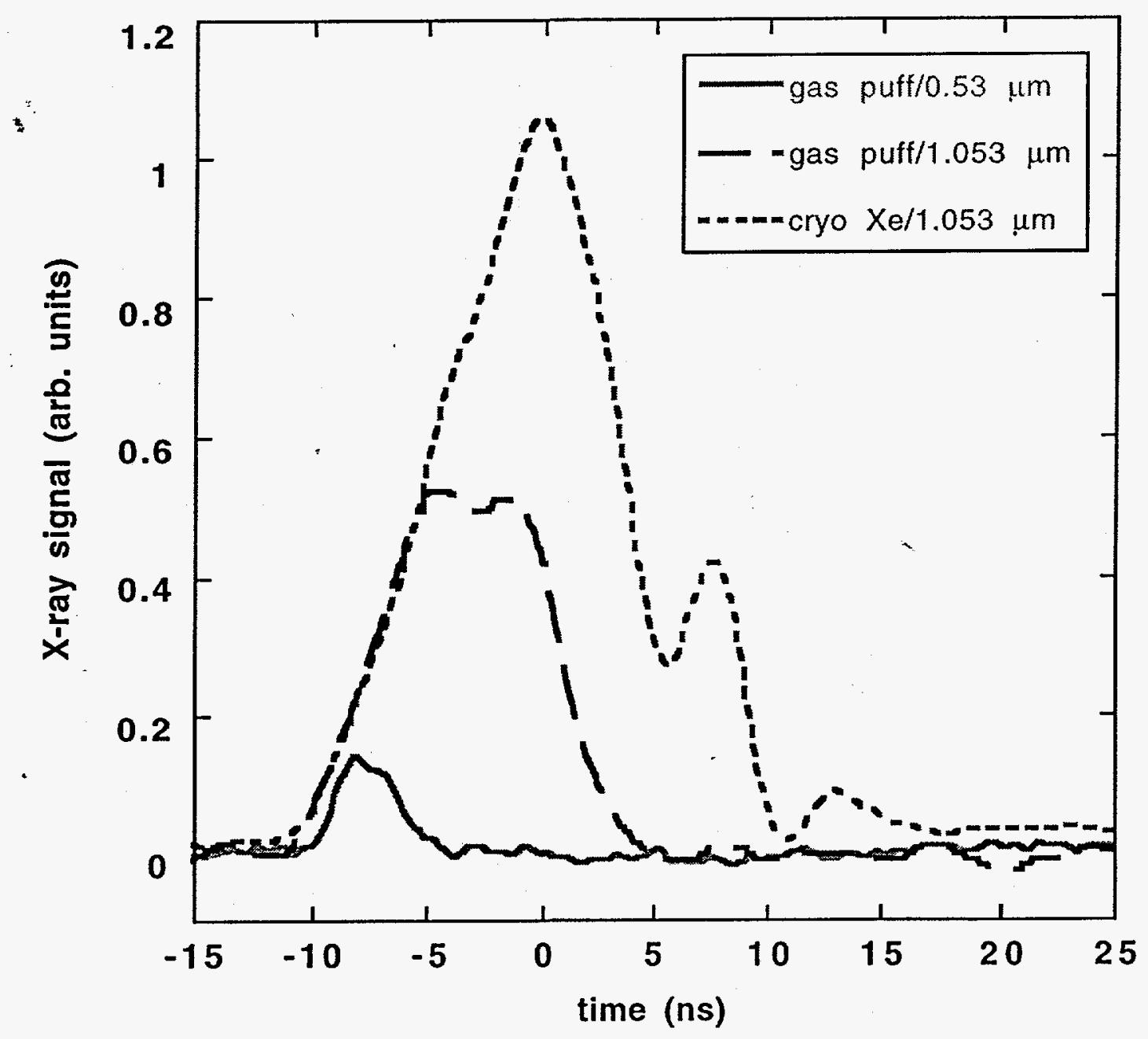

Figure 13 
X-ray sources for proximity lithography
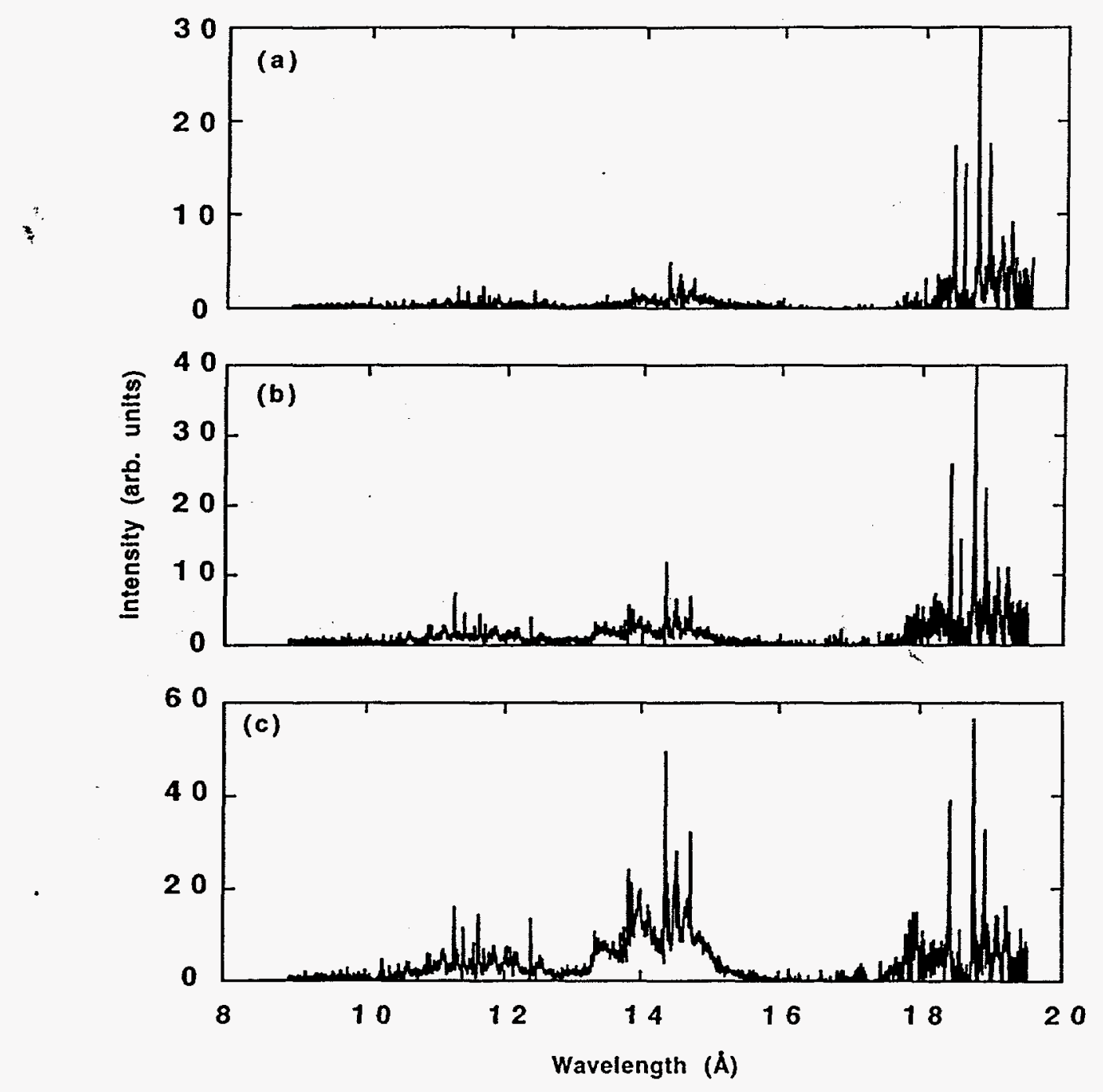

Figure 14 
X-ray sources for proximity lithography
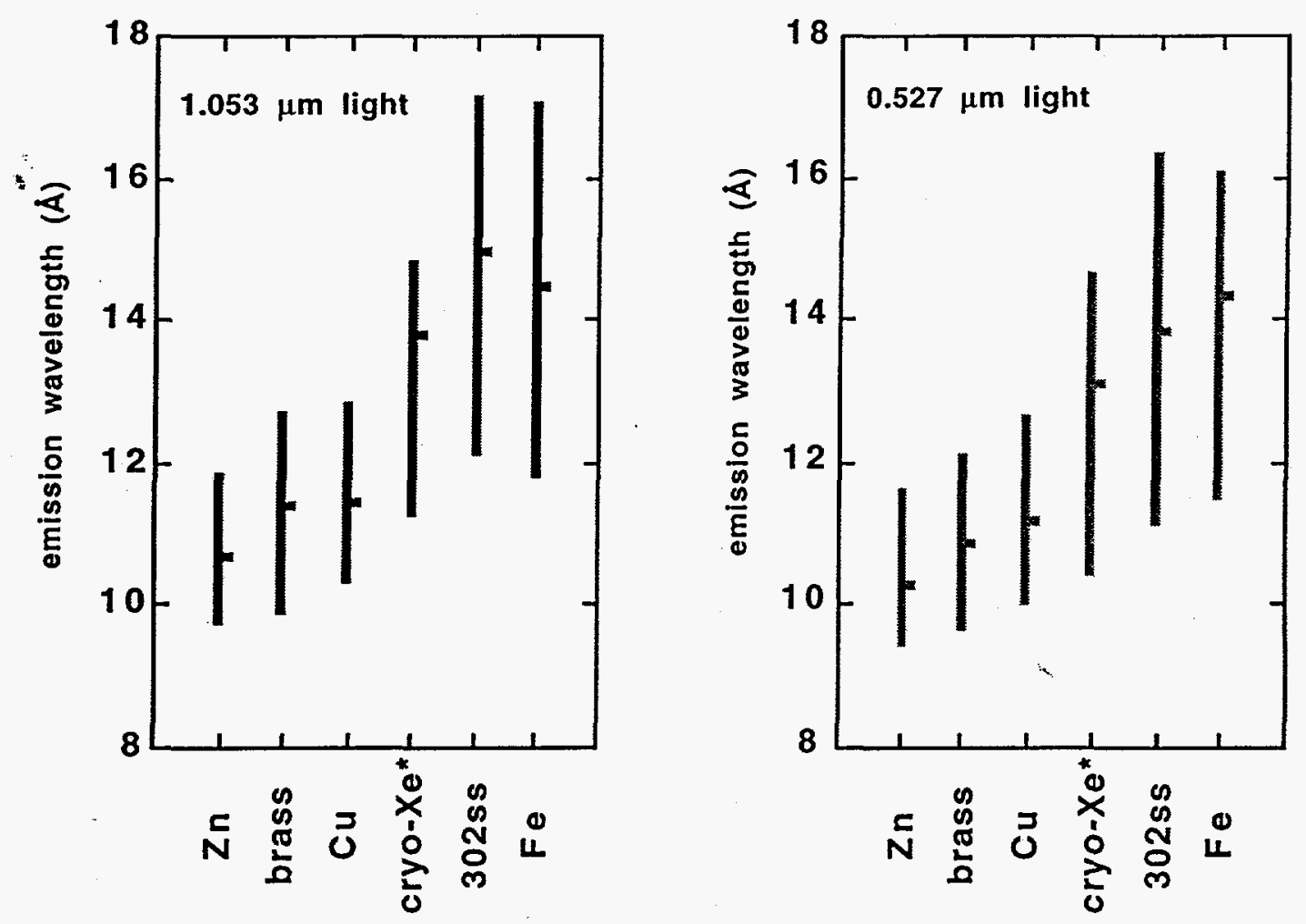

Figure 15 